\title{
Recent advances in global electric circuit coupling between the space environment and the troposphere
}

Article

Accepted Version

Rycroft, M. J., Nicoll, K. A., Aplin, K. L. and Harrison, R. G. (2012) Recent advances in global electric circuit coupling between the space environment and the troposphere. Journal of Atmospheric and Solar-Terrestrial Physics, 90-91. pp. 198211. ISSN 1364-6826 doi:

https://doi.org/10.1016/j.jastp.2012.03.015 Available at https://centaur.reading.ac.uk/31502/

It is advisable to refer to the publisher's version if you intend to cite from the work. See Guidance on citing.

To link to this article DOI: http://dx.doi.org/10.1016/j.jastp.2012.03.015

Publisher: Elsevier

All outputs in CentAUR are protected by Intellectual Property Rights law, including copyright law. Copyright and IPR is retained by the creators or other copyright holders. Terms and conditions for use of this material are defined in the End User Agreement. 


\section{CentAUR}

Central Archive at the University of Reading

Reading's research outputs online 


\title{
Recent advances in global electric circuit coupling between the space environment and the troposphere
}

\author{
Michael J. Rycroft \\ CAESAR Consultancy, 35 Millington Road, Cambridge CB3 9HW, U.K., and \\ Centre for Space, Atmospheric and Oceanic Science, University of Bath, Bath BA2 7AY, \\ U.K.
}

Keri A. Nicoll

Department of Meteorology, University of Reading, Reading RG6 6BB, U.K.

Karen L. Aplin

Department of Physics, University of Oxford, OX1 3RH, U.K.

R. Giles Harrison

Department of Meteorology, University of Reading, Reading RG6 6BB, U.K.

\begin{abstract}
The global atmospheric electric circuit is driven by thunderstorms and electrified rain/shower clouds and is also influenced by energetic charged particles from space. The global circuit maintains the ionosphere as an equipotential at $\sim+250 \mathrm{kV}$ with respect to the good conducting Earth (both land and oceans). Its "load" is the fair weather atmosphere and semi-fair weather atmosphere at large distances from the disturbed weather "generator" regions. The main solar-terrestrial (or space weather) influence on the global circuit arises from spatially and temporally varying fluxes of galactic cosmic rays (GCRs) and energetic electrons precipitating from the magnetosphere. All components of the circuit exhibit much variability in both space and time. Global circuit variations between solar maximum and solar minimum are considered together with Forbush decrease and solar flare effects. The variability in ion concentration and vertical current flow are considered in terms of radiative effects in the troposphere, through infrared absorption, and cloud effects, in particular possible cloud microphysical effects from charging at layer cloud edges. The paper identifies future research areas in relation to Task Group 4 of the Climate and Weather of the Sun-Earth System (CAWSES-II) program.
\end{abstract}

Keywords. thunderstorms, analogue model of global circuit, observations of variations of atmospheric electricity parameters, cluster ion infra-red absorption, radiative transfer, droplet charge, cloud edge charging. 


\section{Introduction}

The topic of the global atmospheric electric circuit has been recently reviewed by Rycroft and Harrison (2011), which thoroughly discussed the background to the subject, and gave a large number of key references to the literature going back more than a hundred years. This paper focuses on more recent work in the field of the global electric circuit, in particular, processes linking the space environment from outside the Earth's atmosphere, to the lower troposphere. In this paper, an overview of the operation of the global electric circuit (both D.C. and A.C. effects) is given, followed by a discussion about the effect of temporal variations in the space environment on the global electric circuit. Several mechanisms by which the global circuit can couple to the lower troposphere are also described, including the radiative action of ions in the troposphere, and charging of low level cloud layers due to vertical current flow in the global circuit. Finally some ideas for future studies in the area are presented.

\section{Modus operandi and parameters of the global circuit}

\subsection{D.C. Circuit}

Thunderclouds, which generate potential differences exceeding $100 \mathrm{MV}$ between the positive charges at their tops and the negative charges near their bottoms (Wormell, 1930), are one important source of upward currents through the atmosphere. They are both a D.C. "battery" and an A.C. generator in the circuit. Each of the $\sim 1000$ thunderstorms active at any one time generates an upward D.C. (Wilson) current of $\sim 1 \mathrm{~A}$ to the ionosphere, which is an excellent conductor, at an equipotential $V_{I}$ of $\sim+250 \mathrm{kV}$ with respect to the Earth (e.g. Rycroft et al., 2000, Singh et al 2011). The conduction current flows down in areas remote from thunderstorms, termed regions of fair weather (i.e. non-cloudy) and semi-fair weather (non-precipitating layer clouds).

These currents flow through the partially conducting atmosphere where ionisation is produced by galactic cosmic rays (GCRs); the vertical conduction current density is termed $\mathrm{J}_{\mathrm{z}}$. Near the land surface, but not the oceans, escaping radon determines the ion concentration and hence the electrical conductivity of the atmosphere in the planetary boundary layer, at heights up to $\sim 2 \mathrm{~km}$ (Pulinets, 2007; Kobylinski and Michnowski, 2007). At sub-auroral latitudes, there is some extra ionisation at $\sim 70 \mathrm{~km}$ altitude produced by relativistic $(\sim 1 \mathrm{MeV})$ electron precipitation from the magnetosphere. Within the polar cap, polewards of the auroral oval, occasional energetic solar proton events (SPEs) of $\sim 100 \mathrm{MeV}$ produce extra ionisation at $\sim 60 \mathrm{~km}$ altitude. The circuit closes through the highly conducting land and sea, and via point discharge currents from pointed objects on the Earth's surface up to the bottom of the thunderclouds. The global circuit is shown schematically in Figure 1.

The increase - by seven orders of magnitude - of the electrical conductivity of the neutral atmosphere, from the Earth's surface up to the lower ionosphere at $80 \mathrm{~km}$ altitude, has been modelled by Rycroft et al. (2007) and Rycroft and Odzimek (2010). It is emphasised both here and elsewhere that the conductivity profile is the most important parameter in establishing the global circuit (Holzworth, 1987; Rycroft et al., 2008). 
By Ohm's law, the conductivity and the electrical conduction current density $\left(\mathrm{J}_{\mathrm{Z}} \sim 2\right.$ $\mathrm{pA} / \mathrm{m}^{2}$ ) in the fair (and semi-fair) weather regions determine the vertical electric field $\mathrm{E}$ there. This electric field points downwards; the potential gradient (PG) is conventionally considered positive in fair weather, typically $\sim 130 \mathrm{~V} / \mathrm{m}$ in unpolluted air at the Earth's surface. Going up into the atmosphere, the vertical electric field reduces in magnitude. The ionospheric potential, $\mathrm{V}_{\mathrm{I}}$, can be estimated by integrating measurements of the vertical electric field $\mathrm{E}(\mathrm{z})$ made by a balloon or aircraft-borne instrument from the surface up to the ionosphere (Markson, 1986). Markson and Price (1999) have considered how such results might be related to the mean global temperature, since the behaviour of thunderclouds is controlled by thunderstorm updraughts which depend upon the temperature of the air at ground level below them. This physical process provides one link between atmospheric electricity and climate change, a crucially important topic for society today (Gray et al., 2010).

In the model of Rycroft et al. (2007), also discussed by Rycroft et al. (2008), the potential at $60 \mathrm{~km}$ altitude is only $24 \mathrm{~V}$ less than the assumed ionospheric potential of $+250,000$ $\mathrm{V}$. These two potentials are the same to within one part in $10^{4}$. Thus, we may, to a good approximation, term the $60 \mathrm{~km}$ level as being the height of the electrosphere. In actuality, the electric currents find it preferable to continue going upwards into a region of ever increasing conductivity, rather than to flow horizontally. This statement is true through the lower ionosphere, even through the dynamo region at 100 to $130 \mathrm{~km}$.

The ionosphere is considered to be an equipotential, except over the polar regions due to the interaction of the solar wind with the geomagnetic field. That situation has been considered in Fig. 2 of Tinsley et al. (2007) and Fig. 1 of Zhou and Tinsley (2010). As the southward component of the interplanetary magnetic field increases from 0 to $7 \mathrm{nT}$, there exists a dawn-to-dusk potential difference of up to $-150 \mathrm{kV}$ across the northern and southern polar caps (i.e. within the auroral ovals). A potential difference of this magnitude is likely to be present during a strong geomagnetic storm. For a dawn-to-dusk component of the interplanetary magnetic field between $-3 \mathrm{nT}$ and $+3 \mathrm{nT}$, there is also a potential difference between the northern and southern polar caps of between $+15 \mathrm{kV}$ and $-15 \mathrm{kV}$. A complete model of the global circuit which includes these effects quantitatively has yet to be constructed.

The concept of the equipotential ionosphere at middle latitudes was investigated by comparing simultaneous measurements of $\mathrm{V}_{\mathrm{I}}$ made from two widely separated locations the research ship "Meteor" in the Atlantic, and Weissenau, Germany (shown in Figure 2 (a)). Figure 2(b) shows, as black dots, the $\mathrm{V}_{\mathrm{I}}$ measurements, made from balloon platforms from the Meteor and Weissenau, during several weeks in 1969. There is a clear linear relationship between the two data sets. Also shown in Figure 2 is the relationship with the surface measurement of PG, given in V/m, from Lerwick, Shetland Islands, in the extreme north of the U.K. (shown by overlaid contours; see Harrison and Bennett, 2007). The consistency between measurements from the three different sites demonstrates that: 
(i) a common equipotential surface exists above the Atlantic Ocean and Germany, consistent with global electric circuit theory, and

(ii) the surface PG at Lerwick is related to the ionospheric potential above.

It is important to realise that most, $\sim 95 \%$, of the atmospheric columnar resistance (obtained by integrating the inverse of the conductivity from the surface up to a particular height) lies below $10 \mathrm{~km}$ altitude. And half of the total resistance lies in the planetary boundary layer, at heights $<2 \mathrm{~km}$. Therefore, the most important part of the load in the global circuit is the boundary layer within $2 \mathrm{~km}$ of the Earth's surface. For the Rycroft et al. (2007) model conductivity profile, the total columnar resistance to the ionosphere is $167 \mathrm{POhms} \mathrm{m}^{2}$. Because of this fact, most of the positive charge in the atmosphere occurs close to the surface; it is not found on the upper conducting plate of the capacitor formed between the Earth and the ionosphere.

As well as being strongly influenced by ionisation, the columnar resistance depends on aerosol concentration and cloud cover. Zhou and Tinsley (2010) used a global electric circuit model with an aerosol and cloud scheme to investigate the effect of such phenomena on the global circuit. Their findings show that aerosols can increase the global columnar resistance by up to $60-90 \%$, and have their greatest effect in the continental boundary layer. In contrast to the large changes caused by aerosol, the effect of clouds on the global columnar resistance was at most $10 \%$, primarily caused by low level clouds. Experimental evidence for a cloud effect on columnar resistance has been demonstrated by Nicoll and Harrison (2009a), using co-located measurements of $\mathrm{J}_{\mathrm{z}}$ and cloud cover from a site in Reading, U.K. $\mathrm{J}_{\mathrm{z}}$ was found to be $12 \%$ lower during days with thick overcast conditions compared to days with thin overcast cloud, suggesting an increased columnar resistance when thick cloud was present.

There is another important D.C. current generator in the global circuit; this is due to electrified rain/shower clouds (shown in Figure 1) which generally bring negative charge to the Earth's surface. The shower cloud contribution is believed to be a fraction (up to about a half) of that of thunderstorms. This topic has been discussed by Rycroft et al. (2007), and it is discussed further in Section 3.2 in relation to recent observations.

Recent investigations have applied the global circuit framework to monitoring earthquakes. Denisenko et al. (2008) used an exponential variation of the atmospheric conductivity in their theoretical calculation of electric fields up through the atmosphere and into the ionosphere where the conductivity is more appropriately represented by a tensor quantity. They then applied this theory to a hypothetical electric field variation in the vicinity of the epicentre of an earthquake. Ampferer et al. (2010) followed up that work, and showed that there would be no appreciable electric field signal from an earthquake at satellite altitudes. Harrison et al. (2010) and Pulinets and Ouzounov (2010) discussed two other possible mechanisms involving atmospheric electricity whereby earthquake-associated signals might affect the ionosphere above the epicentre, the former through conduction current density changes. 


\subsection{Fluctuations and A.C. effects}

The most important sources of A.C. electromagnetic waves within the atmospheric and magnetospheric global circuits, which couple the troposphere to the Earth's plasma environment, are due to lightning. (However, the lowest frequency wave sources occurring in geospace are found in the magnetosphere; these Ultra Low Frequency (ULF, $<3 \mathrm{~Hz}$ ) waves are called magnetic pulsations.) The radio waves emitted by cloud-toground (CG) lightning flashes, known as atmospherics, or "sferics" for short, are strong in the Extremely Low Frequency (ELF, $3 \mathrm{~Hz}-3 \mathrm{kHz}$ ), Very Low Frequency (VLF, 3 $30 \mathrm{kHz}$ ) and Low Frequency (LF, $30-300 \mathrm{kHz}$ ) bands.

In the ELF band, Schumann resonances of the dielectric Earth-ionosphere cavity are excited at 8, 14, 20, $26 \ldots \mathrm{Hz}$ (Rycroft, 1965). The Earth-ionosphere waveguide exhibits a cut-off at $\sim 1.8 \mathrm{kHz}$, and at higher harmonics, which explains the distinctive frequencytime characteristics of night-time sferics, termed "tweeks" (Kumar et al., 2009). Some ELF/VLF electromagnetic energy from lightning enters the ionosphere and is guided by ducts of enhanced plasma density through the plasmasphere. It is dispersed as it propagates in the whistler-mode along geomagnetic field lines to the opposite hemisphere. These whistlers can be interpreted to derive information on the plasma density distribution in the magnetosphere (Lemaire et al., 1998). Plasma instabilities in the magnetosphere generate whistler-mode ELF/VLF emissions, such as chorus and hiss (Trakhtengerts and Rycroft, 2008). Inan et al. (2010) have provided a valuable review of lightning-generated phenomena and related ionospheric perturbations.

The enormous range of spatial scales involved in global circuit phenomena is illustrated in Figure 3(a) (Rycroft and Harrison, 2011). Processes of interest, shown as vertical words at their scales and appropriate heights, include point discharge currents, corona, charging within thunderclouds and semi-fair weather clouds, and orographically induced processes. Figure 3(b) shows a similar figure giving the temporal scales, different processes being shown as vertical words, and different physical phenomena are shown as dark horizontal words. In Figure 3(b) the boundary between D.C. and A.C. phenomena is placed at $\sim 200 \mathrm{~s}$. This is the characteristic time constant of the global circuit, the product of its capacitance and its resistance.

\subsection{Extremely energetic phenomena}

Another possible source of perturbations to the global circuit may arise from processes occurring with upward moving electrons (Shao et al., 2010) above intra-cloud (IC) lightning discharges; Maggio et al. (2009) have estimated the charge transferred by IC and CG lightning flashes. A beam of electrons may be accelerated to high enough energies to create a terrestrial gamma ray (TGF) flash as upward bremsstrahlung radiation when the electrons collide with the nuclei of atmospheric atoms. This phenomenon is identified in Figure 3(b); the topic is covered briefly in Section 3.1 of Rycroft and Harrison (2011). Smith et al. (2011) consider that such a TGF event is rare, occurring for only one IC discharge in a hundred or a thousand, whereas Ostgaard (2011) considers that they occur for each and every IC discharge. Carlson et al. (2010) have discussed the production of a burst of neutrons by a TGF. 
Tsuchiya et al. (2007) have presented observations made on the ground of gamma ray bursts which indicate that electrons can be accelerated beyond $10 \mathrm{MeV}$ prior to $\mathrm{CG}$ discharges. Roussel-Dupre et al. (2008) have reviewed both the conventional electrical breakdown of a gas and runaway breakdown which "involves an avalanche of electrons that are collimated by the applied (electric) field to form an electron beam". "One of the unique signatures of runaway breakdown is the strong gamma ray flux produced by the beam interaction with the gas". Milikh and Roussel-Dupre (2010) have reviewed the role of runaway breakdown in the initiation and development of lightning discharges. Gurevich et al. (2002) and Fullekrug et al. (2011) have discussed the generation of LF radiation by energetic electrons above thunderclouds accelerated by runaway processes, which transport about $-10 \mathrm{mC}$ upwards.

\subsection{Effects at different latitudes}

Figure 4 summarises the different latitude zones involved in electrical phenomena in the atmosphere and near-Earth space environment. Plotted as dots in Figure 4 are the fractions of the Earth's area calculated from the equator up to the latitudes shown; these are points on the first quarter of one period of a sine curve. Thus thunderstorms in the tropics and out to $30^{\circ}$ of latitude (diamond shaped point) occur over half the Earth's surface (note that $\sin 30^{\circ}=0.5$ ). Within this region is the region out to $11^{\circ}$ geomagnetic latitude, considered by Kartalev et al. (2004, 2006) and Rycroft et al. (2005) who discussed upward currents from thunderstorms at the magnetic equator, and their effect on the ionosphere below the F-region peak ( $\mathrm{L} \sim 1.04)$. Kobea et al. (1998) discussed the equatorial electrojet as a part of the global magnetospheric electric circuit. It is important to note that, over South America, the magnetic equator lies between 2 and $12^{\circ}$ south of the geographic equator whereas, for Africa and South East Asia (see next Section), the geomagnetic equator lies to the north of the geographic equator.

Inputs to the atmosphere from the magnetosphere occur due to the precipitation of outer Van Allen radiation belt electrons (Baker et al., 1994) at $\mathrm{L}>3$ to beyond the plasmapause, which lies at L 4 (Lemaire et al., 1998), and even to the auroral zone at $\mathrm{L}$ 7 (Meng et al., 1991); here L is the McIlwain (1961) parameter which specifies a particular geomagnetic field line (or flux tube). In addition to that caused by the precipitation of Van Allen radiation belt electrons, ionisation is created by very energetic charged particles from the Sun within the auroral oval, i.e. inside the polar cap, at L > 7 (Meng et al., 1991). The entire region polewards of L 3 covers only $20 \%$ of the Earth's surface area.

\section{Lightning}

\subsection{Geographical distribution}

The long term spatial distribution of lightning has been well studied from space (Christian et al., 2003). There are three major centres of activity, over South East Asia (sometimes termed the maritime continent), Africa, and South America. Thunderstorm activity peaks at $\sim 1500$ local time each day, i.e at $\sim 07,14$ and 20 Universal Time. This 
is the explanation for the so-called Carnegie curve, present in atmospheric electrical data measured at clear air sites, which shows the variation of thunderstorm activity with Universal Time (see, e.g., MacGorman and Rust, 1998, Figure 1.10). The number of lightning flashes over land, especially over Africa, is typically a hundred times greater than over the tropical oceans. The number of lightning flashes of all types (cloud-toground, CG, return strokes, RS, and intra-cloud, IC, flashes) is $\sim 44 \mathrm{~s}^{-1}$, as a global average value (Christian et al., 2003). Mareev et al. (2008) have considered the role of CG and IC discharges as drivers of transient currents in the global circuit.

\subsection{Thunderstorms relative to other generators in the global circuit}

Liu et al. (2010) have used data from the Tropical Rainfall Measuring Mission (TRMM) to study the geographical distribution of rainfall from thunderstorms, from electrified rain/shower clouds, and from non-electrified rain/shower clouds. They found that thunderstorms contribute most to the rainfall over the land, whereas non-electrified rainfall dominates over the oceans. The UT variation of rainfall over land shows an excellent agreement with the Carnegie curve. Most electrified rain/shower clouds occur over the maritime continent, followed by the Americas and, lastly, over Africa. Liu et al. (2010) conclude that "it seems unlikely that the contribution of the electrified shower clouds to the global circuit will be either completely dominant or entirely negligible in comparison with the thunderstorm contribution".

Considerable investigation into global circuit generators has been made in a series of papers by Mach et al. during recent years. Mach et al. (2009) studied observations made during 850 flights over electrified clouds and thunderstorms. They found that the mean value of the upward current above a storm was $0.8 \mathrm{~A}$, with the median being $0.27 \mathrm{~A}$. Mach et al. (2010) determined the mean total upward conduction (Wilson) current above storms over land and producing lightning was 1.0 A and, over oceans, 1.6 A. For storms without lightning they found corresponding values of $0.13 \mathrm{~A}$ and $0.39 \mathrm{~A}$. They also noted that a storm over land had a lightning flash rate of 2.2 per minute, but only 0.8 per minute over the oceans.

Combining these data sets with optical lightning counts made from space (see Christian et al., 2003; Rycroft and Harrison, 2011), Mach et al. (2011) concluded that the mean contributions to the global electric circuit from land and ocean thunderstorms are $1.1 \mathrm{kA}$ and $0.7 \mathrm{kA}$, respectively. The contributions to the global circuit from electrified rain/shower clouds are $0.04 \mathrm{kA}$ and $0.22 \mathrm{kA}$ for land and ocean storms, respectively. The mean total conduction current is $2.0 \mathrm{kA}$. This means that, of the storms contributing to the global circuit, 1100 are land storms with lightning, 390 are ocean storms with lightning, 330 are land storms without lightning, and 530 are ocean storms without lightning (Mach et al., 2011). These new results should improve the development of global circuit models such as those of Rycroft et al. (2007) and Odzimek et al. (2010) considerably. 


\subsection{Positive cloud-to-ground strokes}

Williams et al. (2006) have presented diagrams illustrating the paths of different types of lightning. Their Figure 2(b) shows a positive cloud-to-ground (+CG) discharge from the top of a thundercloud to ground, whereas their Figure 2(c) depicts a discharge from the bottom of a horizontally extended thundercloud. This latter situation relates to the later stages of Mesoscale Convective Systems (MCSs) which are very effective in generating sprites above them. (Their Figure 2(d) shows an intra-cloud discharge up to the positive charge at the top of a thundercloud, which could generate a beam of energetic electrons that could lead to an upward gamma-ray burst, as mentioned in Section 2.3.)

Because positive cloud-to-ground lightning flashes have stronger and longer-lived continuing currents following the impulsive currents of the return strokes, they are much more important for the global circuit than the many times more numerous negative cloudto-ground flashes (Rycroft et al., 2007, Rycroft and Odzimek, 2009 (their Figure 3), 2010). Saba et al. (2010) have published a diagram (their Figure 6) showing the duration of the continuing currents (CC) for $104 \mathrm{CG}$ discharges carrying positive charge to ground (+CG discharges). They found that the median duration was almost $100 \mathrm{~ms}(0.1 \mathrm{~s})$. They also showed that $+\mathrm{CGs}$ are much less frequent than $-\mathrm{CGs}$, but that their peak return stroke current $\left(I_{p}\right)$ is much larger, often $>50 \mathrm{kA}$.

Rycroft et al. (2007) investigated the effects of both negative and positive lightning on the global circuit using their PSpice model. They found that -CGs contributed only $7 \%$ to maintaining the ionospheric potential, and that + CGs with continuing currents lasting 90 ms decreased it by $\sim 5 \%$. Thus, overall, lightning contributes only $\sim 2 \%$ to maintaining the ionospheric potential. In relation to discussions since Wormell (1930, 1953) published his "electrical balance sheet" at the Earth's surface, this is an important result.

\subsection{Sprites}

Another result derived from the Rycroft et al. (2007) model is that, $1 \mathrm{~ms}$ after a large (peak current $I_{p}=50 \mathrm{kA}$, Rakov and Uman, 2003) +CG discharge, a column sprite is created by electrical breakdown at $80 \mathrm{~km}$ altitude. This is shown as the starred region in Figure 5 (a), where the continuing current is $0.2 \mathrm{kA}$. In Figure 5 (b), the continuing current is $0.5 \mathrm{kA}$ which enables positive streamers to progress downwards; this is shown by the region of diamond shapes going down to $42 \mathrm{~km}$. Regions where negative streamers (see Luque and Ebert, 2010) can propagate upwards are shown by the region with crosses. Figure 5 (c), with a continuing current of $2 \mathrm{kA}$, shows electrical breakdown as the starred region between 10 and $90 \mathrm{~ms}$ after the causative lightning discharge. Positive streamers progress downwards for the duration of the continuing currents, which is taken to be $90 \mathrm{~ms}$. For a $2 \mathrm{kA} \mathrm{CC}$, electrical breakdown occurs $10 \mathrm{~ms}$ after the lightning return stroke, from $67 \mathrm{~km}$ down to $55 \mathrm{~km}$, which it reaches in about $100 \mathrm{~ms}$ (Rycroft and Odzimek, 2010). This simulation represents a carrot sprite; it occurs when the charge moment change of the lightning discharge exceeds the threshold value of 350 C.km. 
Rycroft and Odzimek $(2009,2010)$ showed that the effect of a single sprite on the ionospheric potential $\mathrm{V}_{\mathrm{I}}$ was to decrease it by only $\sim 1 \mathrm{~V}$. Such a small change is unlikely to have any significant effect on the global circuit. As A.C. sources in the global circuit, Pasko et al. (1998), Rycroft and Odzimek (2010) and Li and Cummer (2011) have considered the ELF radiation produced by currents flowing in sprites. Pasko et al. (1998) stated that a sprite produces a comparable amount of ELF radiation to that radiated by the causative lightning discharge. Li and Cummer (2011) discussed streamer processes in sprites; further, they estimated the space charge within a sprite to be of the order of $\mathrm{mC}$.

\subsection{Schumann resonances}

Radiation from lightning - and sprites - at $\sim 8 \mathrm{~Hz}$, where the wavelength is comparable with the circumference of the Earth, excites Schumann resonances of the Earthionosphere cavity. Recent investigations by Surkov and Hayakawa (2010) have shown that $+\mathrm{CG}$ lightning activity makes a significant contribution to power spectral density of Schumann resonances, despite their infrequent occurrence rate compared with -CG discharges (Christian et al., 2003; Rycroft et al., 2007).

Further recent research into Schumann resonances has been made by Nickolaenko et al. (2011) who have separated Universal Time and local time variations of the intensity of Schumann resonances observed at three widely separated stations around the world, and also investigated seasonal variations. Whitley et al. (2011) have reported a new global network of four stations with excellent timing accuracy. They have studied the excitation of Schumann resonances by a distant $+\mathrm{CG}$ discharge having a large $\mathrm{CC}$ and also by the sprite which it caused.

\section{Effect of the space environment on the global electric circuit}

\subsection{Solar cycle variations}

The flux of GCRs entering the Earth's atmosphere is essential to the global electric circuit, as this is the main source of ionisation above the surface. Figure 6 (a) shows a time series of GCR flux from 1955 to the present day, at altitudes between 25 and $30 \mathrm{~km}$, obtained from balloon flights made by the Lebedev Institute (Bazilevskaya, 2011; see Stozhkov et al., 2009). The multiple lines represent different geomagnetic latitudes (described in terms of the cut off rigidity, Rc, which is related to the energy of the incoming GCR), from which it is clear that penetration of cosmic rays into the atmosphere depends strongly on location (due to the shielding effect of the geomagnetic field). Also evident from Figure 6 (a) (and Figure 6 (b), which shows the neutron count rate measured at Oulu, Finland, indicating the flux of cosmic rays of $>0.8 \mathrm{GV}$ ), is the 11 year solar cycle, which is much more pronounced for low Rc (high geomagnetic latitudes) than high ones. In the troposphere the GCR flux at high latitudes is about $20 \%$ smaller during solar maximum conditions than solar minimum. The latter data in Figure 6 (a) and (b) demonstrate the extent of the recent deep solar minimum (from 2005 to 2010), when the highest GCR flux for more than 50 years occurred.

The clear dependency of GCR ionisation on solar activity means that the global electric circuit is modulated over the 11 year solar cycle. The ionospheric potential and neutron 
counter measurements of cosmic rays have been observed to be positively correlated. This result derives from observations made during a period of intensive ionospheric potential $\left(\mathrm{V}_{\mathrm{I}}\right)$ soundings carried out in the late 1960s and early 1970s (Mulheisen, 1977; Markson and Muir, 1980; Markson 1981). Figure 7 compares measurements of atmospheric electrical parameters with neutron counter measurements made from Climax, Colorado. Figure 7 (a) shows an upward trend of $\sim 15 \%$ in $\mathrm{V}_{\text {I }}$ for a $10 \%$ increase in neutron count rate. Any related variation is much less apparent in surface atmospheric electricity measurements, due to variations in the columnar resistance from air mass changes, near-surface air pollution and weather. Figure 7(b) shows the scatter present in the daily conduction current density (Wilson) measurements made at Kew (shown as grey points), compared with the Climax neutron counter data; little variation is seen with the neutron counter rate.

Investigations into the smoke pollution effects at the Kew Observatory site (Harrison, 2005) have indicated that, in periods of cleaner air, the columnar resistance shows less variability, and hence global circuit effects may be less obscured. One measure of the air's cleanliness is the air conductivity, which was also measured at this site. Extrapolation of air conductivity against smoke concentration measurements (Harrison, 2006, his Figure 2) indicates that relatively smoke free air is associated with air conductivity of $10 \mathrm{fSm}^{-1}$ or greater. Few daily measurements have air conductivity greater than $5 \mathrm{fSm}^{-1}$ in this data set, as it is a polluted site (see Figure 8(b) of Rycroft et al., 2008). However, selecting the upper $2 \%$ of conductivity data (38 values, median day of year in the selected data 166, with inter-quartile range 85 , shown as black points in Figure 7 (b)) does reveal an upward trend with neutron count rate ( 14\% for a 10\% change in the neutron count rate.)

Figure 7(b) hints at a solar modulation of $\mathrm{J}_{\mathrm{z}}$ as measured from Kew, London. Similar results have been found by Markson and Muir (1980), who reported a 30\% solar cycle variation in $J_{Z}$ in phase with the GCR variation, whilst Harrison and Usoskin (2010) found surface measurements of $\mathrm{J}_{\mathrm{Z}}$ measured at Lerwick, Shetland, to be $\sim 17 \%$ less during solar maxima. Since $\mathrm{J}_{\mathrm{Z}}$ flows vertically from the ionosphere to the Earth's surface, this current flow provides a method of coupling between the upper and lower atmosphere. Recent work shows $\mathrm{J}_{\mathrm{Z}}$ flows through clouds (Nicoll and Harrison, 2009a) which may affect the clouds as it does so, therefore suggesting a possible mechanism whereby solar activity can modulate low level cloud cover (e.g., Tinsley, 2000) (see Section 5.3 for more detail).

\subsection{Short term solar variations}

As well as modulation of the global electric circuit on an 11 year cycle, short term variations in the output of the Sun have also been observed to affect the global electric circuit, mainly from solar flares and solar magnetic sector boundary crossings. From measurements made at Mauna Loa in Hawaii, Cobb (1967) observed an increase in PG and $\mathrm{J}_{\mathrm{Z}}$ by $10 \%$ during periods of solar flares, compared to "quiet Sun" days. During a period of multiple solar flares, $\mathrm{J}_{\mathrm{z}}$ increased by $75 \%$ of its normal value, for a period of 6 hours. Similar results were found by Reiter (1989), who observed increases in $J_{z}$ of about $20 \%$ following large solar flares. In addition to surface measurements, observations of atmospheric electrical responses to Solar Energetic Particle (SEP) events in the 
stratosphere from balloon platforms have been made by Holzworth and Mozer (1979), Holzworth et al. (1987) and Kokorowski et al. (2006).

Although evidence of a solar influence on atmospheric electrical parameters exists, the solar-electrical coupling mechanisms are not well understood. For example, solar flares often produce an influx of SEPs into the Earth's atmosphere, whilst at the same time perturbing the geomagnetic field so that the GCR flux is reduced (an event known as a Forbush Decrease). Since both SEPs and GCRs produce ionisation, it is often difficult to determine the precise cause of the atmospheric electrical changes. More measurements of atmospheric electrical responses to short term solar perturbations are therefore required, as well as measurements over a wide latitudinal range to determine how the global electric circuit changes globally.

\section{Observations of atmospheric effects related to the global electric circuit}

\subsection{Atmospheric ions}

The electrical conductivity of the atmosphere is due to the presence of bipolar ions between the surface and the ionosphere. Close to the continental surface, ion production is dominated by natural radioactivity emitted from the ground. The ion production rate from GCRs increases with height, with a maximum at altitudes of $\sim 15$ to $20 \mathrm{~km}$. Due to their charge, GCRs are deflected by the geomagnetic field. Therefore the ionisation rate depends on the magnetic latitude; it is greatest at high magnetic latitudes.

Ionisation occurs when an electron is separated from a molecule of oxygen or nitrogen, leaving the molecule positively charged, e.g., $\mathrm{N}_{2}{ }^{+}$. The electron is then quickly captured by neutral electrophilic molecules, creating a negative ion, e.g., $\mathrm{O}_{2}^{-}$. The primary ions stabilise through clustering with other polar molecules such as ammonia, water, and organics, and are then known as cluster ions (Harrison and Carslaw, 2003).

Attachment of these cluster ions to aerosol particles and water droplets charges them. There is evidence that the presence of electric charge on aerosol particles and cloud droplets can affect their behaviour, particularly for droplet-particle, particle-particle and droplet-droplet collisions. Additionally, the ions themselves may absorb infra-red radiation via bending and stretching of their hydrogen bonds, potentially altering the Earth's energy balance. The radiative effect of ions will be discussed in Section 5.2, and charge effects on clouds in Section 5.3.

\subsection{Radiative effects of atmospheric ions}

Atmospheric ions are clusters of core positive ions or electrons attached to electrophilic molecules, with polar ligands hydrogen bonded to the core ion. There are numerous possible ligands, represented here for simplicity as $\mathrm{X}$ and $\mathrm{Y}$ with typical species $\mathrm{O}^{2-}(\mathrm{X})_{\mathrm{n}}$ or $\mathrm{H}_{3} \mathrm{O}^{+}(\mathrm{Y})_{\mathrm{n}}$, where $n<10$ (e.g. Harrison and Tammet, 2008). The hydrogen bonds in the clusters absorb infra-red radiation, the physical basis by which neutral species like the water dimer $\left(\mathrm{H}_{2} \mathrm{O}\right)_{2}$ are thought to contribute to atmospheric radiative transfer (e.g., Ptashnik, 2008). Infra-red absorption of molecular ions is already well-established in astrophysics (e.g., Thaddeus et al., 2008), but so far only one ion $\left(\mathrm{NO}^{+}\right)$is included in the 
HITRAN database of radiatively active species in the terrestrial atmosphere (e.g., Rothman et al., 2009). However, as infra-red absorption from the gas phase protonated water dimer $\mathrm{H}_{3} \mathrm{O}^{+}\left(\mathrm{H}_{2} \mathrm{O}\right)_{2}$, a common species of atmospheric ion, has been both predicted and observed in the laboratory, a small radiative effect from atmospheric cluster ions is also expected (Klemperer and Vaida, 2006).

Quantitative prediction of the infra-red absorption from other atmospheric cluster ions is limited computationally by the large number of isomers of each species (Likholyot et al., 2007), and the wide, poorly understood, and highly variable mixture of cluster ion species (Harrison and Tammet, 2008). An order of magnitude estimate of the potential radiative effect of atmospheric ions can be obtained by considering their integrated concentration in an atmospheric column compared to the water vapour dimer. Figure 8 shows calculated abundance profiles of atmospheric ions and water dimers. The columnar concentration of the water vapour dimer is six orders of magnitude greater than for cluster ions, so the absorption from atmospheric ions will be much lower than the $3 \mathrm{Wm}^{-2}$ expected from the dimer (Ptashnik, 2008). Hence, the absorption of cluster ions is likely to be comparable to the $\mu \mathrm{Wm}^{-2}$ to $\mathrm{mWm}^{-2}$ estimated for some neutral atmospheric complexes (Kjaergaard et al., 2003), which requires sensitive instrumentation for detection.

Laboratory spectroscopy measurements of cluster ion absorption were carried out by Carlon (1982) and Aplin and McPheat (2005). Carlon (1982) identified absorption in the 8-12 $\mu \mathrm{m}$ continuum region (near the peak of the terrestrial black body radiation spectrum) in humid, ion-rich air. Aplin and McPheat (2005) generated a mixture of ions, with similar electrical mobility to those found naturally in the atmosphere, with a corona source at room temperature and $20 \%$ humidity. Infra-red absorption from the enhanced ion concentrations $\left(10^{12} \mathrm{~m}^{-3}\right)$ relative to ambient $\left(10^{8} \mathrm{~m}^{-3}\right)$ was $1-3 \%$ in two broad bands centred on 9.15 and $12.3 \mu \mathrm{m}$. The enhanced ion concentrations represent a column integrated concentration of $10^{13} \mathrm{~m}^{-2}$, less than the total atmospheric columnar ion concentration of $\sim 10^{14} \mathrm{~m}^{-2}$. These experiments also suggest that detection of an integrated absorption effect from a column of atmospheric cluster-ions is possible.

Infra-red absorption in atmospheric air was measured using a bespoke filter radiometer tuned to the ion absorption band centred on $9.15 \mu \mathrm{m}$ (Aplin and McPheat, 2008) at Reading University Atmospheric Observatory, U.K., a well-instrumented meteorological and atmospheric electrical station. In the experiment, described in more detail by Aplin (2008), bipolar ion concentrations $n$ were calculated from 5 minute averages of $1 \mathrm{~s}$ samples of the atmospheric Potential Gradient $F$ and conduction current $J_{z}$ using

$$
n=\frac{F}{e \mu J_{Z}}
$$

where $e$ is the elementary charge, and $\mu$ the mean ion mobility, $1.5 \mathrm{~cm}^{-2} \mathrm{~V}^{-2} \mathrm{~s}^{-1}$ at the same site (Harrison and Aplin, 2007). 
The filter radiometer voltage signal, $V_{r}$, was conditioned with a low-noise amplifier (Harrison and Knight, 2006) with gain $G$ of 500, and the instrument's body temperature $T_{r}$ was measured with a platinum resistance thermometer. Another instrument ${ }^{1}$, adjacent to the filter radiometer, was used to measure the broadband downwelling longwave radiation, from which the blackbody atmospheric brightness temperature $T_{b}$ was determined. Absorption in the filter radiometer's passband $L_{\lambda}$ is given by

$$
L_{\lambda}=\sigma\left(\frac{\tau}{G}\right)^{2}\left\{\frac{G}{k \tau \sigma} V_{r}-\left(T_{b}{ }^{4}-T_{r}{ }^{4}\right)\right\}
$$

where $\sigma$ is Stefan's constant, $\tau$ is the radiometer's transmissivity (5.8\%), and $k$ is the radiometer sensitivity $\left(29.3 \mu \mathrm{VWm}^{-2}\right)$. The approach of referencing $L_{\lambda}$ to the atmospheric brightness temperature means that a positive signal indicates emission in the sensitive wavelength range above the radiometer, whereas negative response indicates absorption with respect to the blackbody background.

The filter radiometer's response to ion concentrations was explored under nocturnal, quiescent periods to avoid contributions from solar heating and aerosol lofting. To minimize the effect of any neutral water vapour absorption in the passband, saturated (foggy) and clear sky, constant humidity and temperature data were selected for comparison - see Figure 9. In both circumstances, a response of $\sim 100 \mu \mathrm{Wm}^{-2}$ per ion was seen, indicating that the total absorption of radiation in the $9.15 \mu \mathrm{m}$ band from local cluster-ion concentrations of $10^{8}$ to $10^{9} \mathrm{~m}^{-3}$ could be $1-10 \mathrm{mWm}^{-2}$, a small, but nonnegligible contribution. Further work is needed to assess the effects of changing ionisation in an atmospheric column above the filter radiometer.

\subsection{Cloud effects}

Stratiform cloud edges are expected to become charged due to vertical ion current flow, $\mathrm{J}_{\mathrm{z}}$, from the global atmospheric electric circuit (Zhou and Tinsley, 2007). A layer of cloud creates a vertical gradient in the electrical conductivity of the air, from high conductivity clear air to low conductivity air inside the cloud, due to ion-droplet attachment. To maintain a constant value of $\mathbf{J}_{\mathrm{z}}$ and satisfy Ohm's law, the electric field, $\mathrm{E}$, inside the cloud must increase from its clear air value. This creates a vertical gradient in the electric field at the upper and lower edges of the cloud, which, according to Gauss' law of electrostatics, is associated with space charge, $\rho$, in these regions.

The generation of space charge on cloud edges is dependent upon the flow of $\mathrm{J}_{\mathrm{z}}$ through a cloud layer, which is most likely to occur for clouds of large horizontal extent (e.g., layer clouds). This has been confirmed experimentally by Nicoll and Harrison (2009a), using co-located surface measurements of cloud and $J_{z}$ at a U.K. site. Confirmation of the existence of charge on stratiform cloud edges aloft has also been shown from recent balloon-borne measurements of atmospheric electrical parameters, using an inexpensive, disposable charge sensor (Nicoll and Harrison, 2009b). Figure 10 shows vertical profiles from the ascent - (a) and (b); and descent - (c) and (d), of the balloon-borne charge sensor

\footnotetext{
${ }^{1}$ Kipp and Zonen CNR1 net radiometer
} 
through a long lived layer of stratocumulus cloud, over Reading, U.K. The charge sensor was flown alongside a standard meteorological radiosonde, measuring pressure, temperature, relative humidity (RH) and GPS position. From Figures 10 (b) and (d), it is evident that a layer of space charge (of magnitude $\sim 100 \mathrm{pCm}^{-3}$ ) existed at the top of the cloud layer (shown by the temperature inversion and change in $\mathrm{RH}$ at $2.8 \mathrm{~km}$ altitude), on both the ascent and descent stages. From the GPS position data, it is known that these profiles were obtained $65 \mathrm{~km}$ apart, due to horizontal movement of the balloon, suggesting that the cloud edge electrification was occurring over a wide region.

On a different occasion, balloon measurements through a stratocumulus cloud layer, which were made at the same time as an instrumented aircraft flight, showed a clear layer of space charge at the cloud base (Nicoll and Harrison, 2010). Cloud droplet measurements from the aircraft demonstrated that charge was present only in the region where the cloud droplet number concentration (and thus the conductivity) was changing. The theoretical space charge expected from Gauss' law was shown to be in good agreement with the measured space charge, again supporting a cloud edge charging mechanism from $J_{Z}$ flow through clouds.

\subsection{Charge and cloud microphysics}

Generation of space charge on cloud edges leads to the transfer of charge to cloud droplets and aerosol particles in these regions, which can influence several cloud microphysical processes. Charge influences particle-particle collisions, such as the collection of particles and droplets by other droplets, and inhibits evaporation from droplets. These microphysical mechanisms could link layer cloud edge charging with the cloud properties, as illustrated in Figure 11. In the first type of cloud microphysical charge effects, affecting the phase of the droplets, charged particles were suggested to have their collision efficiencies ${ }^{2}$ with liquid droplets electrically-enhanced (shown in Figure 11(a)), known as electro-scavenging (Tinsley, 2000). This proposal was based on theory and laboratory experiments showing that particle charging considerably enhances the collection of aerosol by water droplets (Wang et al., 1978; Tripathi, 2000; Tinsley et al., 2001). Such effects have been parameterised for use in cloud models by Tripathi et al. (2006).

In the specific case of super-cooled water clouds, electro-scavenging could increase freezing by enhancing the rate of contact nucleation (Harrison, 2000; Tinsley et al., 2000; Tripathi and Harrison, 2002), with an associated change in the amount or location of latent heat release as freezing occurs. The second set of cloud charge effects concerns increasing droplet size (or number), either through enhancing droplet formation, or through an increase in droplet-droplet coalescence. These processes are not restricted to super-cooled clouds. Electro-activation (shown in Figure 11 (b)), can facilitate droplet formation by reducing the vapour pressure inhibiting evaporation and lowering the supersaturation at which the droplet will grow rather than evaporate (Harrison and Ambaum,

\footnotetext{
${ }^{2}$ Collision efficiency quantifies how readily a collision occurs between drops (or particles) flowing around other drops.
} 
2008), but substantial charging is required. Droplet-droplet collision efficiency can also be considerably enhanced by charging (Khain et al., 2004), leading to droplet growth by charged coalescence (shown in Figure 11 (c)).

Figure 12 considers the different scenarios of Figure 11 more quantitatively. Firstly, Figure 12 (a) shows the effect of charge on the removal of small particles by water droplets (i.e. aerosol scavenging), as shown in Figure 11 (a), found from the parameterisation of Tripathi et al. (2006). For electrified aerosol particles, the collision efficiency is increased over that for neutral particles. This response is not strongly sensitive to the droplet charge, depending principally on the particle charge and the particle size.

Secondly, (see Figure 12(b)), the effect of charging on droplet formation from water vapour is considered (after Harrison and Ambaum, 2008), as depicted in Figure 11(b). The critical supersaturation is the local vapour supersaturation required for a droplet to become activated, and therefore stable against evaporation. This varies with charging, from the effect of charge in reducing the vapour pressure over the droplet surface. For a large electrostatic effect on critical supersaturation, negligible salt must be dissolved in the droplet, as, for droplets which contain more solute, the effect of dissolved salt is also to reduce the vapour pressure. Hence, this effect can only be expected to be appreciable for pure droplets with substantial charging ( 100 elementary charges per droplet).

Finally, Figure 12(c) shows the collision efficiency between two small charged droplets, as shown schematically in Figure 11(c). This is calculated by the method of superposition (Klimin et al, 1994), through establishing the flow field around the larger droplet and allowing collision through the electric image force (e.g., Khain et al., 2004). Depending on the relative polarity of the droplets, the collision efficiency can be enhanced or inhibited. This effect depends strongly on the sizes of the droplets considered, and diminishes as the droplets become large.

In conclusion, these considerations demonstrate that:

(i) electrical effects on water droplet activation require the special circumstances of substantial charges and pure droplets,

(ii) the collection of charged particles by droplets can be affected by only modest charges on small particles, and

(iii) droplet-droplet collisions appear particularly sensitive to charging, and especially so for interacting small droplets.

Despite these theoretical expectations, because these processes are only considered in isolation from the many others which also occur in the dynamic circumstances of real clouds, the net quantitative consequences of charge effects on cloud microphysical processes and also on cloud macrophysical properties are not known. More research is required in this realm, particularly for small droplet charges and electric fields typical of fair weather, rather than thunderstorm, conditions. 


\subsection{Evidence of charge effects on clouds}

As demonstrated in Section 4, the GCR flux and therefore the global electric circuit and $\mathrm{J}_{\mathrm{Z}}$, are modulated by solar processes, both on an 11 year timescale, and shorter periods. It follows that cloud edge charging, due to the flow of $J_{z}$, may also be influenced by solar processes.

Focusing on short term solar variations, Harrison and Ambaum (2008) detected coincident variations in $J_{z}$ and downward long-wave radiation underneath a stratocumulus layer during a solar flare event. The long wave radiation was found to reduce by $0.3 \mathrm{Wm}^{-2}$ during the event, which was suggested to be due to a change in the height of the cloud base, caused by a change in the cloud droplet charge as a result of the changes in $\mathrm{J}_{\mathrm{Z}}$. Changes in cloud properties during large Forbush events were also reported in Harrison and Ambaum (2010), using surface based observations of cloud cover from Lerwick, Shetland, derived using the diffuse fraction (the ratio of diffuse solar radiation to global solar radiation) (Harrison et al., 2008). For 10 - 12\% reductions in the neutron count rate (from Climax, Colorado) it was found that broken cloud cover became at least $10 \%$ more frequent within one day of a Forbush decrease event. This is consistent with the timescales (a few hours - see Zhou and Tinsley, 2007) expected for a $\mathrm{J}_{\mathrm{Z}}$ effect on cloud microphysical processes to take effect.

\section{Concluding remarks}

In this paper we have discussed many ways in which phenomena occurring near the Earth's surface are coupled to the ionosphere and the near-Earth space environment, and vice versa.

Areas of research in this field requiring further study include:

(i) experimental investigations of the roles of thunderstorms and electrified rain/shower clouds, in different geographical regions, as current sources (generators) for the global atmospheric electric circuit, and also their effects on the ionosphere,

(ii) modelling and experimental investigations of infra-red absorption by cluster ions, and their radiative effects, both in the laboratory and in the real atmosphere

(iii) modelling and experimental studies of the effects of atmospheric electricity on low level clouds and their micro-physical processes, especially the evolution of electrical charges on water droplets in clouds, in the semi-fair weather part of the global circuit,

(iv) the incorporation of cosmic ray processes, solar wind and magnetospheric inputs, stratospheric aerosol processes and cloud cover of different types into improved models of the global circuit,

(v) the investigation of the energy densities of the different processes involved (see Maggio et al., 2009),

(vi) further studies of different influences on the global circuit over the land and over the oceans, 
(vii) the continuing search for signatures in the vertical electric field and the current density observed in the atmosphere and at the Earth's surface in the fair and semi-fair weather regions of (a) solar flares, (b) Forbush decreases, (c) solar proton events, (d) coronal mass ejections (CMEs) and other space weather effects, (e) auroral activity, and (f) gigantic jets (as discussed briefly, but with more references, in Rycroft and Harrison (2011)),

(viii) the effects of gigantic jets (see Chou et al., 2010) on the global circuit - they short circuit the $\sim 5 \%$ of the atmosphere from the cloud top to the ionosphere above the thunderstorm which generates them, and

(ix) ELF radiation of lightning and sprites, and particularly Schumann resonances of the Earth-ionosphere cavity.

An exciting future is guaranteed for studies of these electrodynamic and electromagnetic aspects of coupling from the Earth's surface up to the ionosphere, and also downwards, in the frame of Task Group 4 of the international CAWSES-II program.

Acknowledgements. The authors thank their colleagues on different continents for many fascinating discussions. This paper partly results from an ISSI team project Study of cosmic ray influence upon atmospheric processes.

\section{References}

Ampferer, M., Denisenko, V.V., Hausleitner, W. et al. 2010. Decrease of the electric field penetration into the ionosphere due to low conductivity at the near ground atmospheric layer, Annales Geophysicae 28 779-787

Aplin K.L., 2008. Composition and measurement of charged atmospheric clusters, Space Science Reviews 137 (1-4), 213-224, doi: 10.1007/s11214-008-9397-1

Aplin K.L. and McPheat R.A., 2005. Absorption of infra-red radiation by atmospheric molecular cluster-ions, Journal of Atmospheric and Solar-Terrestrial Physics, 67, 775783, doi:10.1016/j.jastp.2005.01.007

Aplin K.L. and McPheat R.A., 2008. An infrared filter radiometer for atmospheric cluster-ion detection, Review of Scientific Instruments, 79, 106-107, doi: $10.1063 / 1.3002428$

Baker, D.N., Blake, J.B., Callis, L.B., et al. 1994. Relativistic electron acceleration and decay time scales in the inner and outer radiation belts: SAMPEX, Geophysical Research Letters 21, 409-412

Bazilevskaya, G.A., Private communication, 2011 
Carlon, H.R., 1982. Infrared absorption and ion content of moist atmospheric air, Infrared Physics 22, 43-49

Carlson, B.E., Lehtinen, N.G., Inan, U.S., 2010. Neutron production in terrestrial gamma ray flashes, Journal of Geophysical Research 115, A00E19, doi:10.1029/JA014696

Chou, J.K., Kuo, C.L., Tsai, L.Y. et al., 2010. Gigantic jets with negative and positive polarity streamers, Journal of Geophysical Research 115 A00E45, doi:10.1029/2009JA014831

Christian, H.J., Blakeslee, R.J., Boccippio et al., 2003. Global frequency and distribution of lightning as observed from space by the Optical Transient Detector, Journal of Geophysical Research D 108 (1), 4005, doi:10.1029/2002JD002347

Cobb, W . E., 1967. Evidence of solar influence on the atmospheric electrical elements at Mauna Loa Observatory, Monthly Weather Review 95, 905

Denisenko, V.V., Boudjada, M.Y., Horn, M., et al. 2008. Ionospheric conductivity effects on electrostatic field penetration into the ionosphere, Natural Hazards and Earth System Sciences 8 1009-1017

Fullekrug, M. Roussel-Dupre, Symbalisty, E.M.D., Colman, J.J. et al., 2011. Relativistic electron beams above thunderclouds, Atmospheric Chemistry and Physics 11 (15), 77477754

Gray, L.J., Beer, J., Geller, J. et al., 2010. Solar influences on climate, Reviews of Geophysics 48, doi:10.1029/2009RG000282

Gurevich, A.V., Duncan, L.M., Medvedev, et al. 2002. Radio emission due to simultaneous effect of runaway breakdown and extensive air showers, Physics Letters A 301, 320-326

Harrison R.G., 2000. Cloud formation and the possible significance of charge for atmospheric condensation and ice nuclei, Space Science Reviews, 94, 381-396

Harrison, R.G., 2005. Columnar resistance changes in urban air, Journal of Atmospheric and Solar-Terrestrial Physics 67, 763-773

Harrison, R.G., 2006. Urban smoke concentrations at Kew, London, 1898-2004, Atmospheric Environment 40, 3327-3332

Harrison, R.G., Ambaum, M.H.P., 2008. Enhancement of cloud formation by droplet charging, Proceedings of the Royal Society of London A 464, 2561-2573

Harrison, R.G., Ambaum, M.H.P., 2010. Observing Forbush decreases in cloud at Shetland, Journal of Atmospheric and Solar-Terrestrial Physics 72, 1408-1414 
Harrison R.G., Aplin K.L., 2007. Water vapour changes and atmospheric cluster ions, Atmospheric Research 85, 199-208, doi:10.1016/j.atmosres.2006.12.006

Harrison, R.G., Aplin, K., Rycroft, M., 2010. Atmospheric electricity coupling between earthquake regions and the ionosphere, Journal of Atmospheric and Solar-Terrestrial Physics 72 (5-6), 376-381

Harrison, R.G., Bennett, A.J., 2007. Multi-station synthesis of early twentieth century surface atmospheric electricity measurements for upper tropospheric properties, Advances in Geosciences 13, 17-23

Harrison, R.G., Carslaw, K.S., 2003. Ion-aerosol-cloud processes in the lower atmosphere, Reviews of Geophysics 41 (3), 1012, doi:10.1029/2002RG000114

Harrison, R.G., Ingram, W.J., 2005. Air-earth current measurements at Kew, London, 1909-1979, Atmospheric Research 76, 49-64

Harrison, R. G., Knight, J. R., 2006. Thermopile radiometer signal conditioning for surface atmospheric radiation measurements, Review of Scientific Instruments 77 (11), 116105

Harrison R.G., Tammet H., 2008. Ions in the terrestrial atmosphere and other solar system atmospheres, Space Science Reviews 137 (1-4), 107-118, doi:10.1007/978-0-38787664-1_7

Harrison, R. G., Chalmers, N. and Hogan, R. J., 2008. Retrospective cloud determinations from surface solar radiation measurements, Atmospheric Research, 90, 54-62

Harrison, R.G., Usoskin, I., 2010. Solar modulation in surface atmospheric electricity, Journal of Atmospheric and Solar-Terrestrial Physics 72, 176-182

Holzworth, R.H., 1987. Electric fields in the middle atmosphere, Physica Scripta T18, 298, doi:10.1088/0031-8949/1987/T18/030

Holzworth, R. H., Mozer F. S., 1979. Direct evidence of solar flare modification of stratospheric electric fields, Journal of Geophysical Research 84, 363-367

Holzworth, R. H., Norville K. W., Williamson, P. R., 1987. Solar flare perturbations in stratospheric current systems, Geophysical Research Letters 14, 852-855

Inan, U.S., Cummer, S.A., Marshall, R.A., 2010. A survey of ELF and VLF research on lightning-ionosphere interactions and causative discharges, Journal of Geophysical Research 115, A00E36, doi:10/1029/2009JA014775 
Kartalev, M. D., Rycroft, M.J., Papitashvili, V.O., 2004. A quantitative model of the effect of global thunderstorms on the global distribution of ionospheric electrostatic potential, Journal of Atmospheric and Solar-Terrestrial Physics 66, 1233-1240, doi:10.1016/j.jastp.2004.05.012

Kartalev, M.D., Rycroft, M.J., Fullekrug, M., et al. 2006. A possible explanation for the dominant effect of South American thunderstorms on the Carnegie curve, Journal of Atmospheric and Solar-Terrestrial Physics 68, 457-468

Khain, A., Arkhipov, V., Pinsky, M. et al., 2004. Rain enhancement and fog elimination by seeding with charged droplets. Part I: Theory and numerical simulations, Journal of Applied Meteorology 43, 1513-1529

Kjaergaard H., Robinson T.W., Howard D.L., et al. 2003. Complexes of importance to the absorption of solar radiation, Journal of Physical Chemistry A 107, 10680-10686

Klemperer W. and Vaida, V., 2006. Molecular complexes in close and far away, Proceedings of the National Academy of Sciences 28, 10584-10588

Klimin, N.N., Rivkind, V.Ya., Pachin, V.A., 1994. Collision efficiency calculation model as a software tool for microphysics of electrified clouds, Meteorology and Atmospheric Physics 53, 111-120

Kobea, A.T., Amory-Mazaudier, C., Do, J.M., et al. 1998. Equatorial electrojet as part of the global circuit: a case-study from the IEEY, Annales Geophysicae 16, 698-710

Kobylinski, Z., Michnowski, S., 2007. Atmospheric electric and electromagnetic field rapid changes as possible precursors of earthquakes and volcanic eruption: a brief review, Sun and Geosphere 2(1), 43-47

Kokorowski, M., Sample, J.G. , Holzworth, R.H. et al., 2006. Rapid fluctuations of stratospheric electric field following a solar energetic particle event. Geophysical Research Letters 33, L20105

Kumar, S., Deo, A., Ramachandran, V., 2009. Nighttime D-region equivalent electron density determined from tweek sferics observed in the South Pacific Region. Earth, Planets and Space 61, 905-911

Lemaire, J., Gringauz, K.I., Carpenter, D.L., et al. 1998. The Earth's plasmasphere. Cambridge University Press, pp. 374

Li, J., Cummer, S., 2011. Estimation of electric charge in sprites from optical and radio observations, Journal of Geophysical Research 116, A01301, doi:10.1029/2010JA015391 
Likholyot A., Lemke K.H., Hovey J.K, et al. 2007. Mass spectrometric and quantum chemical determination of proton water clustering equilibria, Geochimica et Cosmochimica Acta 71, 2436-2447

Liu, C., Williams, E.R., Zipser, E.J., et al. 2010. Diurnal variations of global thunderstorms and electrified shower clouds and their contribution to the global electrical circuit, Journal of Atmospheric Sciences 67, 309-323, doi:10.1175/2009JAS3248.1

Luque, A., Ebert, U., 2010. Sprites in varying air density: Charge conservation, glowing negative trails and changing velocity, Geophysical Research Letters, 37, L06806, doi:10.1029/2009GL041982

MacGorman, D.R., Rust, W.D., 1998. The electrical nature of storms, Oxford University Press

Mach, D.M., Blakeslee, R.J., Bateman, M.G., et al. 2009. Electric fields, conductivity, and estimated currents from aircraft overflights of electrified clouds, Journal of Geophysical Research 114, D10204, doi:10.1029/JD011495

Mach, D.M., Blakeslee, R.J., Bateman, M.G., et al. 2010. Comparisons of total currents based on storm location, polarity, and flash rates derived from high-altitude aircraft overflights, Journal of Geophysical Research 115, D03201, doi:10.1029/JD012240

Mach, D.M., Blakeslee, R.J., Bateman, M.G., 2011. Global electric circuit implications of combined storm electric current measurements and satellite-based diurnal lightning statistics, Journal of Geophysical Research 116, D05201, doi:10.1029/JD014462

Maggio, C.R., Marshall, T.C., Stolzenburg, M., 2009. Estimations of charge transferred and energy released by lightning flashes, Journal of Geophysical Research 114, D14203, doi:10.1029/.2008JD011506

Makino M. and Ogawa T., 1985. Quantitative estimation of global circuit, J. Geophys. Res., 90, 5961-5966

Mareev, E.A., Yashunin, S.A., Davydenko, S.S., et al., 2008. On the role of transient currents in the global electric circuit, Geophysical Research Letters 35, L15810, doi:10.1029/2008GL034554

Markson, R., 1981. Modulation of the Earth's electric field by cosmic radiation, Nature 291, 304-308.

Markson, R., 1986. Tropical convection, ionospheric potentials and global circuit variation, Nature 320, 588-594 
Markson R., Muir, M., 1980. Solar wind control of the Earth's electric field, Science 208, 979-990

Markson, R., Price, C., 1999. Ionospheric potential as a proxy index for global temperature, Atmospheric Research 51, 309-314

McIlwain, C.E., 1961. Coordinates for mapping the distribution of magnetically trapped particles, Journal of Geophysical Research 66, 3681-3691

Meng, C.I., Rycroft, M.J., Frank, L.A. (eds), 1991. Auroral Physics, Cambridge University Press, pp. 496

Milikh, G., Roussel-Dupre, R., 2010. Runaway breakdown and electrical discharges in thunderstorms, Journal of Geophysical Research 115, A00E60, doi:10.1029/JA014818

Mühleisen, R.P., 1977. The global circuit and its parameters. In: Electrical Processes in Atmospheres, Dolezalek,H., Reiter, R. (eds), Dr. Dietrich Steinkopff Verlag, Darmstadt, $467-476$

Nickolaenko, A.P., Yatsevich, E.I., Shvets, A.V., et al. 2011. Universal and local time variations deduced from simultaneous Schumann resonance records at three widely separated observatories, Radio Science 46, RS5003, doi:10.1029/2011RS004663

Nicoll, K.A., 2010. Coupling between the global atmospheric electric circuit and clouds, Ph.D. thesis, University of Reading, pp. 231

Nicoll, K.A., Harrison, R.G., 2009a. Vertical current flow through extensive layer clouds, Journal of Atmospheric and Solar-Terrestrial Physics 71, 2040-2046

Nicoll, K.A., Harrison, R.G., 2009b. A lightweight balloon-carried cloud charge sensor, Reviews of Scientific Instruments 80, 014501

Nicoll, K.A., Harrison, R.G., 2010. Experimental determination of layer cloud edge charging from cosmic ray ionisation, Geophysical Research Letters 37, L13802, doi:10.1029/2010GL043605

Odzimek, A., Lester, M., Kubici, M., 2010. EGATEC: A new high-resolution engineering model of the global atmospheric electric circuit - Currents in the lower ionosphere, Journal of Geophysical Research 115, D18207, doi:10.1029/JD013341

Ostgaard, N., Private communication (2011)

Pasko, V.P., Inan, U.S., Bell, T.F., et al. 1998. Mechanism of ELF radiation from sprites, Geophysical Research Letters 25, 3493-3496 
Ptashnik, I., 2008. Evidence for the contribution of water dimers to the near-IR water vapour self-continuum, Journal of Quantitative Spectroscopy and Radiative Transfer 109 (5), 831-852

Pulinets, S., 2007. Natural radioactivity, earthquakes, and the ionosphere, EOS, Transactions American Geophysical Union 88 (20), 217, doi:10.1029/2007EO200001

Pulinets, S., Ouzounov, D. 2010. Lithosphere-Atmosphere-Ionosphere Coupling (LAIC) model - An unified concept for earthquake precursors validation. Journal of Asian Earth Sciences 41, 371- 382

Rakov, V.A., Uman, M.A., 2003. Lightning: Physics and effects, Cambridge University Press, pp. 687

Reiter, R., 1989. Solar activity influence on atmospheric electricity and on some structures in the middle atmosphere, in: Handbook for MAP, 29, Lastovicka, J. (ed.), SCOSTEP, University of Illinois, Urbana, U.S.A., p.168

Rothman L.S., Gordon, I.E., Barbe A. et al., 2009. The HITRAN 2008 molecular spectroscopic database, Journal of Quantitative Spectroscopy and Radiative Transfer 110 (9-10), 533-572

Roussel-Dupre, R., Colman, J.J., Symbalisty, E., et al. 2008. Physical processes related to discharges in planetary atmospheres, Space Science Reviews 137 (1-4), 51-82, doi:10.1007/978-0-387-87664-1_5

Rycroft, M.J., 1965. Resonances of the Earth-ionosphere cavity observed at Cambridge, England, Radio Science, Journal of Research National Bureau of Standards 69D, 10711081

Rycroft, M.J., Israelsson, S., Price, C., 2000. The global atmospheric electric circuit, Journal of Atmospheric and Solar-Terrestrial Physics 62, 1563-1576

Rycroft, M. J., M. D. Kartalev, V. O. Papitashvili, et al. 2005. On the effect of nearequatorial thunderstorms on the global distribution of ionospheric potential, Advances of Space Research 35 (8), 1450-1460, doi:10.1016/j.asr.2005.05.030

Rycroft, M.J., Harrison, R.G., 2011. Electromagnetic atmosphere-plasma coupling: The global atmospheric electric circuit, Space Science Reviews 1-22, doi:10.1007/s11214011-9830-8

Rycroft, M.J., Harrison, R.G., Nicoll, K.A., et al. 2008. An overview of Earth's global electric circuit and atmospheric conductivity, Space Science Reviews 137, 83-105, doi:10:1007/978-0-387-87664-1_6 
Rycroft, M.J., Odzimek, A., 2009. The impact of lightning flashes and sprites on the Earth's global electric circuit: An overview of recent modelling results, in Coupling of Thunderstorms and Lightning Discharges to Near-Earth Space, Crosby, N.B., Huang, T.Y., Rycroft, M.J. (eds), American Institute of Physics Conference Proceedings, CP 1118, $124-135$

Rycroft, M.J., Odzimek, A., 2010. Effects of lightning and sprites on the ionospheric potential, and threshold effects on sprite initiation, obtained using an analog model of the global atmospheric electric circuit, Journal of Geophysical Research 115, A00E37, doi10.1029/2009JA014758

Rycroft, M.J., Odzimek, A., Arnold, N.F., et al., 2007. New model simulations of the global atmospheric electric circuit driven by thunderstorms and electrified shower clouds: the roles of lightning and sprites, Journal of Atmospheric and Solar-Terrestrial Physics 69, 2485-2509

Saba, M.M.F., Schulz, W., Warner, T.A., et al., 2010. High-speed video observations of positive lightning flashes to ground, Journal of Geophysical Research 115, D24201, doi:10.1029/2010JD014330

Shao, X.-M., Hamlin, T., Smith, D.M., 2010. A closer examination of terrestrial gammaray flash-related lightning processes, Journal of Geophysical Research 115, A00E30, doi:10.1029/JA014835

Singh, A.K., Siingh, D., Singh, R.P., et al. 2011. Electrodynamical coupling of Earth's atmosphere and ionosphere: An overview, International Journal of Geophysics 2011, doi:10.1155/2011/971302

Smith, D.M., Dwyer, J.R., Hazelton, B.J., et al., 2011, The rarity of terrestrial gamma-ray flashes, Geophysical Research Letters 38, L08807, doi:10.1029/2011GL046875

Stozhkov, Y.I., Svirzhevsky, N.S., Bazilevskaya, G.A., et al., 2009. Long-term (50 years) measurements of cosmic ray fluxes in the atmosphere, Advances in Space Research 44, 1124-1137

Surkov, V.V., Hayakawa, M., 2010. Schumann resonances excitation due to positive and negative cloud-to-ground lightning, Journal of Geophysical Research 115, D04101, doi:10.1029/2009JD012539

Thaddeus P., Gottlieb, C.A., Gupta, H., et al., 2008. Laboratory and astronomical detection of the negative molecular ion $\mathrm{C}_{3} \mathrm{~N}^{-}$, Astrophysical Journal, 677, 1132, doi: $10.1086 / 528947$

Tinsley, B.A., 2000. Influence of solar wind on the global electric circuit, and inferred effects on cloud microphysics, temperature and dynamics in the troposphere, Space Science Reviews 94, 231-258 
Tinsley, B.A., Rohrbaugh, R.P., Hei, M. et al., 2000. Effects of image charges on the scavenging of aerosol particles by cloud droplets and on droplet charging and possible ice nucleation processes, Journal of Atmospheric Sciences 57, 2118-2134

Tinsley, B.A., Rohrbaugh, R.P., Hei, M., 2001. Electroscavenging in clouds with broad droplet size distributions and weak electrification, Atmospheric Research 59-60, 115135

Tinsley, B.A., Burns, G.B., Zhou, L, 2007. The role of the global electric circuit in solar and internal forcing of clouds and climate, Advances in Space Research 40, 1126-1139

Trakhtengerts, V.Y., Rycroft, M.J., 2008. Whistler and Alfven mode cyclotron masers in space, Cambridge University Press, pp. 354

Tripathi, S.N., 2000. Removal of charged aerosols, Ph.D. thesis, University of Reading, U.K.

Tripathi, S.N., Harrison, R.G., 2002. Enhancement of contact nucleation by scavenging of charged aerosol particles, Atmospheric Research 62, 57-70

Tripathi, S.N., Vishnoi, S., Kumar, S. et al., 2006. Computationally efficient expressions for the collision efficiency between electrically charged aerosol particles and cloud droplets, Quarterly Journal of the Royal Meteorological Society 132, 1717-1731

Tsuchiya, H., Enoto, T., Yamada, S. et al., 2007. Detection of high-energy gamma rays from winter thunderclouds, Physical Review Letters 99, 165002

Wang, P.K., Grover, S.N., Pruppacher, H.R., 1978. On the effects of electric charge on the scavenging of aerosol particles by clouds and small raindrop, Journal of Atmospheric Sciences 35, 1735- 1743

Whitley, T., Fullekrug, M., Rycroft, M. J.., et al., 2011. Worldwide extremely low frequency magnetic field sensor network for sprite studies, Radio Science 46, RS4007, doi:10.1029/2010RS004523

Williams, E.R., Boldi, R., Bor, J., et al. 2006. Lightning flashes conducive to the production and escape of gamma radiation to space, Journal of Geophysical Research 111, D16209, doi:10.1029/2005JD006447

Wormell, T.W., 1930, Vertical electric currents below thunderstorms and showers, Proceedings of the Royal Society A 127, 567-590

Wormell, T.W., 1953, Atmospheric electricity: some recent trends and problems, Quarterly Journal of the Royal Meteorological Society 79, 3-38 
Zhou, L., Tinsley, B.A., 2007. Production of space charge at the boundaries of layer clouds, Journal of Geohpysical Research 112, D11203, doi:10.1029/2006JD007998

Zhou, L., Tinsley, B.A., 2010. Global circuit model with clouds, Journal of Atmospheric Sciences 67, 1143-1156 


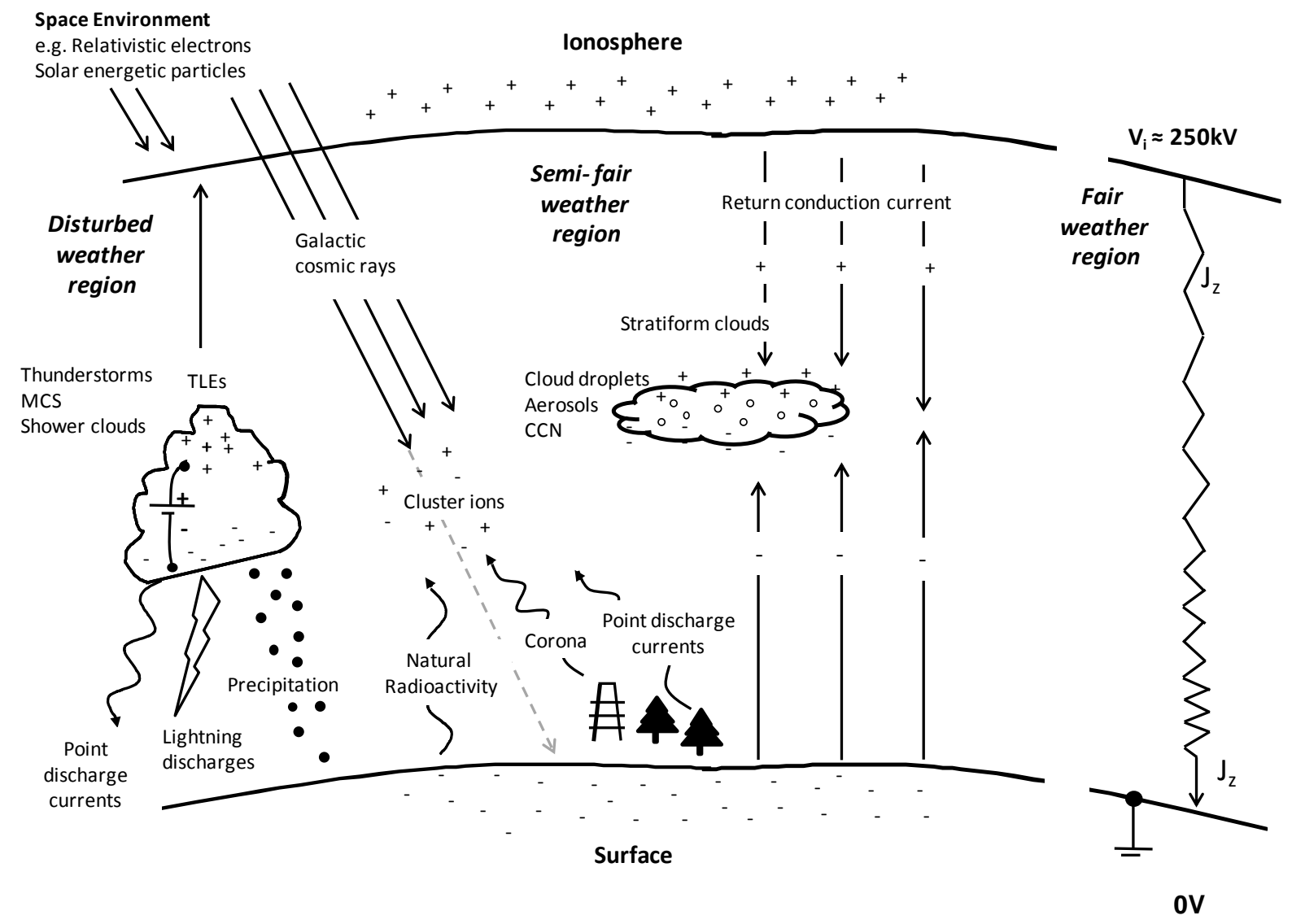

Fig. 1. Diagram showing various processes of importance in the global electric circuit. Charge separation in thunderstorms, which occur in disturbed weather regions, creates a substantial potential difference between the highly conducting regions of the ionosphere and the Earth's surface. The positive potential of the ionosphere (positive with respect to the Earth's surface) is distributed to fair weather and semi-fair weather regions, where a small current (whose density is $J_{z}$ ) flows vertically. When this current flows through clouds it generates charge near the upper and lower cloud edges, which can influence cloud microphysical processes. (In this diagram, Mesospheric Convective Systems, which are large scale thunderstorms late in their evolution and which favour sprite generation above them, are indicated by MCS ; sprites are one example of Transient Luminous Events (TLEs); Cloud Condensation Nuclei are shown as CCN). 
(a)

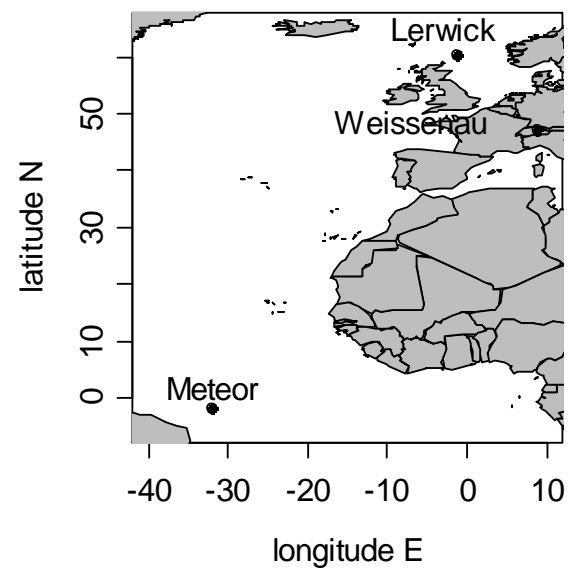

(c)

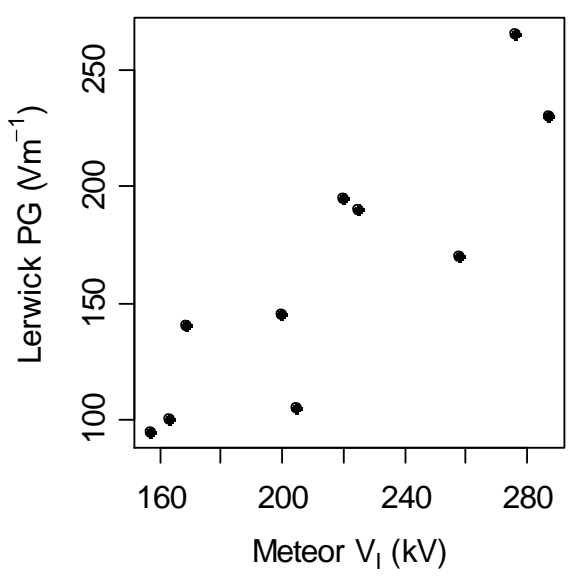

(b)

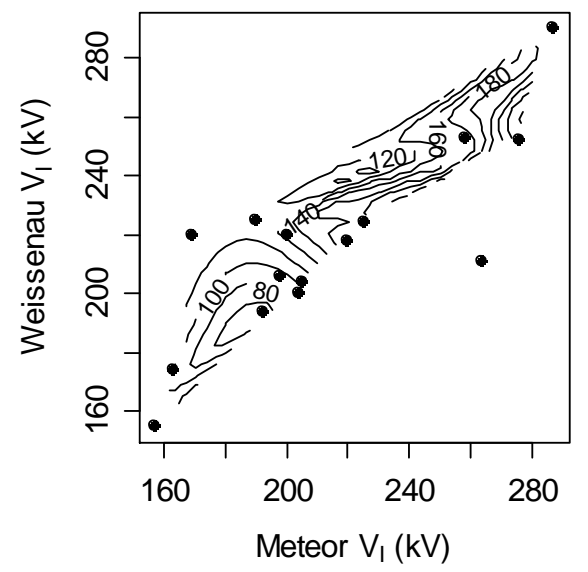

(d)

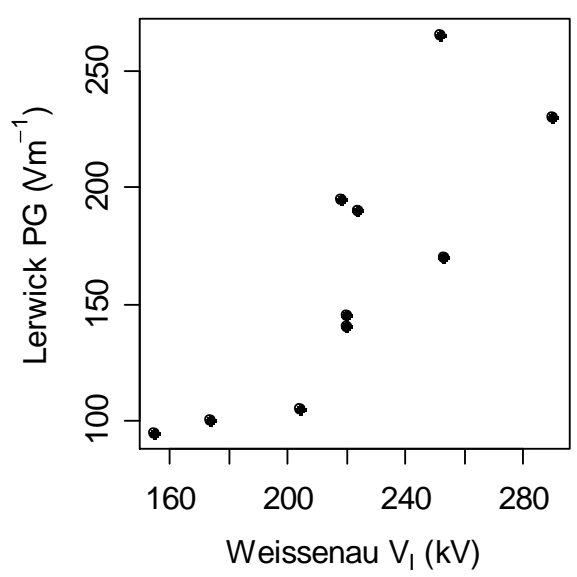

Fig. 2. (a) Position of the Meteor research ship between $17^{\text {th }}$ March and $7^{\text {th }}$ April 1969. (b) Simultaneous daily soundings of ionospheric potential $V_{\mathrm{I}}$ made from the Meteor, and from Weissenau (points). Contours of PG (plotted in $\mathrm{Vm}^{-1}$ ) simultaneous with the Weissenau and Meteor soundings, measured at Lerwick during conditions of no hydrometeors, are overlain (adapted from Harrison and Bennett (2007)). (c) and (d), Lerwick PG values against the two separate sources of $V_{\mathrm{I}}$ measurement, obtained at the same time. 
(a)

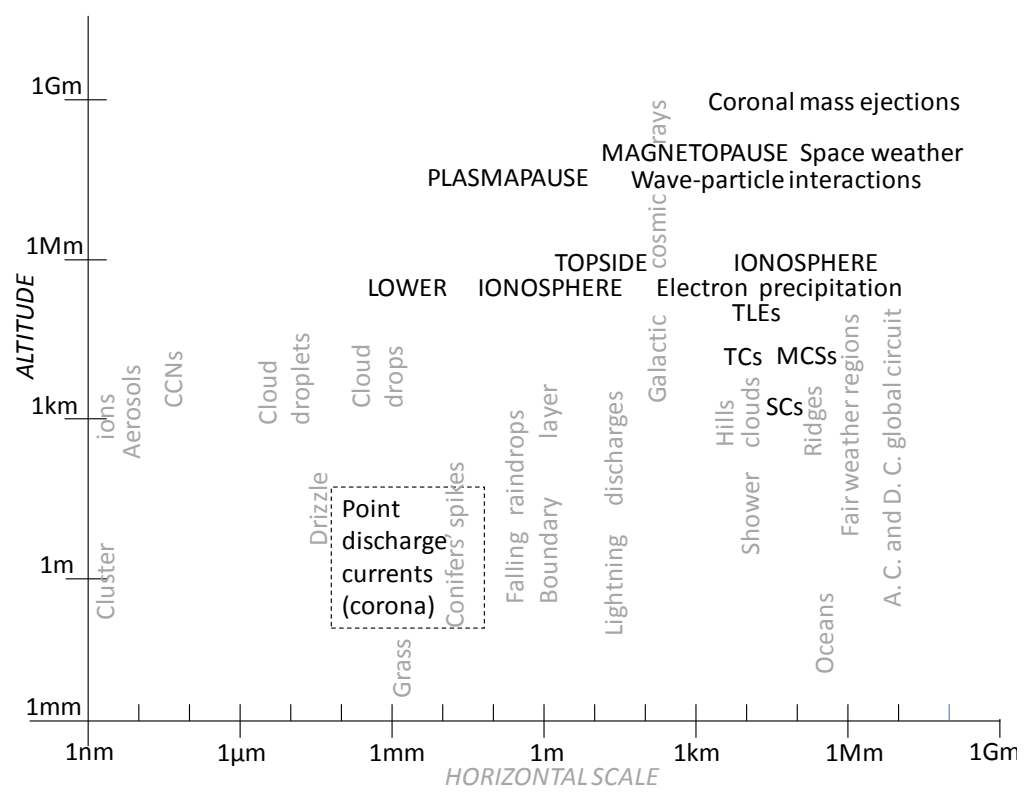

(b)

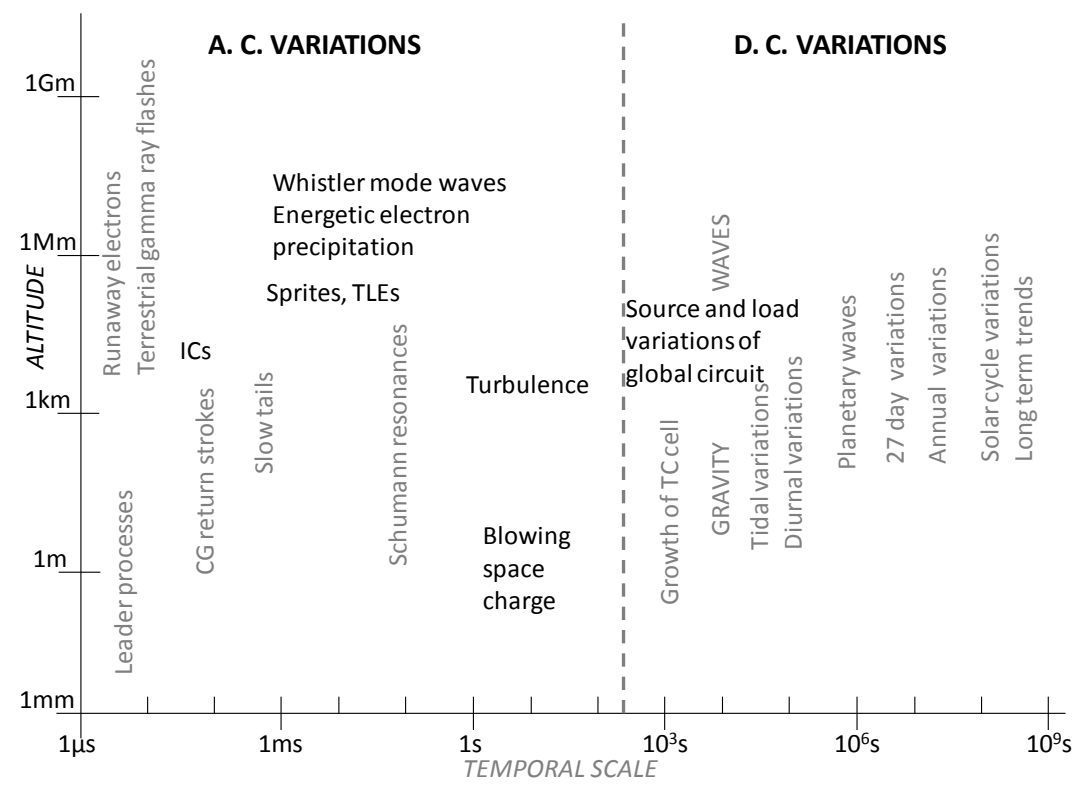

Fig. 3. Diagrams demonstrating (a) the large range of horizontal and vertical scales involved in electrical phenomena, and (b) the large range of time scales involved in processes occurring at different altitudes in the Earth's atmosphere and near-space environment. In (a), horizontal words (in black) show different regions at different altitudes where different physical processes occur, whereas vertical words (in grey) show features with a certain horizontal scale which act over the altitude range indicted. In (b), horizontal words (in black) denote processes occurring over different timescales, and vertical words (in grey) represent phenomena which occur on different temporal scales over different altitude ranges. (Taken from Rycroft and Harrison (2011).) 


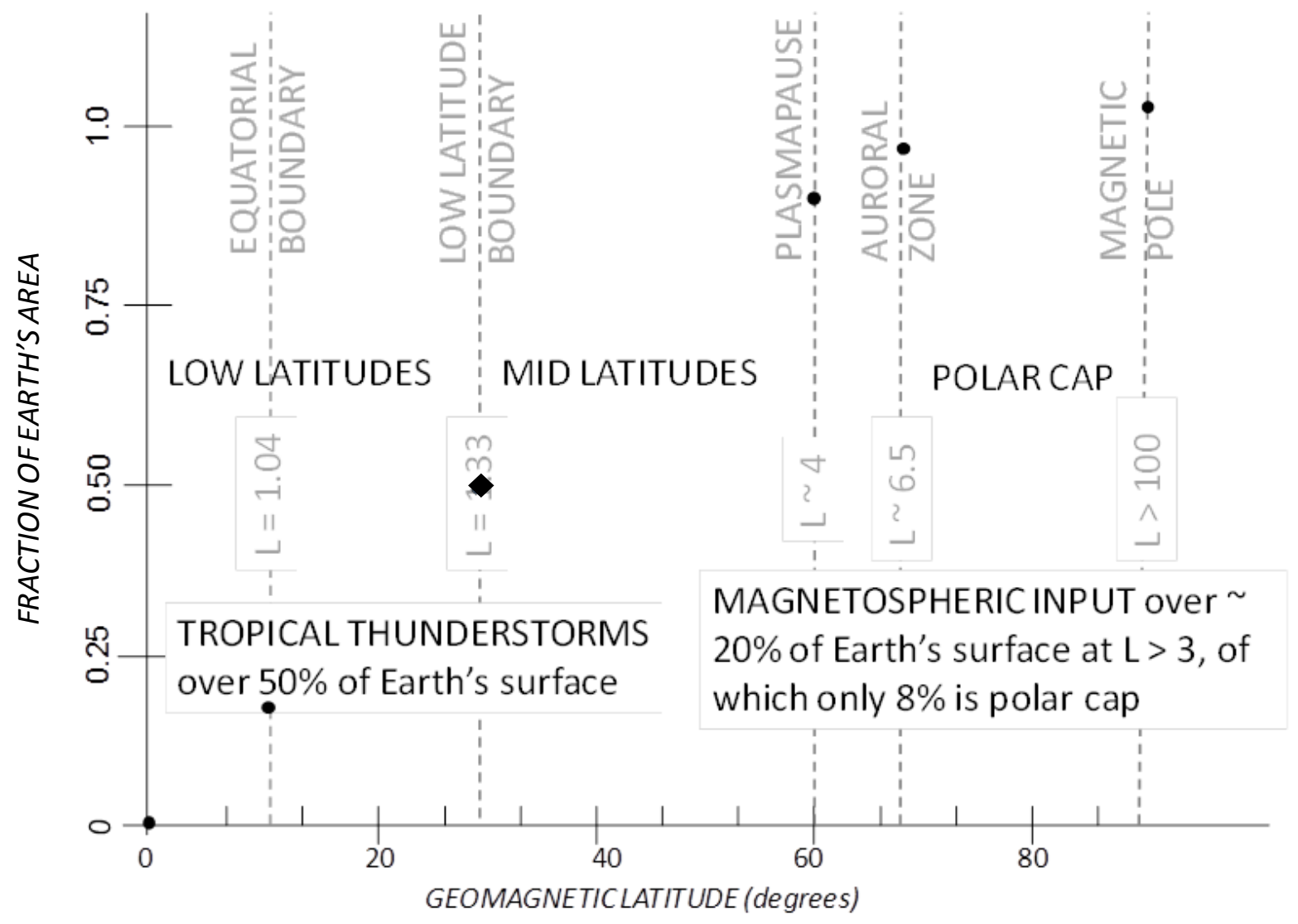

Fig. 4. Diagram depicting latitude zones involved in electrical phenomena in the atmosphere and near-Earth space environment. The black points plot the fraction of the Earth's surface measured from the equator out to some values of latitude; they lie on a sine curve. Vertical words (in grey) show significant boundaries in the Earth's atmosphere and near-Earth space environment system. Most thunderstorms occur in the tropical regions, at latitudes up to $\sim 30^{\circ}$. Magnetospheric input to the system occurs above only $\sim 20 \%$ of the Earth's surface, at magnetic latitudes greater than $53^{\circ}$. 
(a)

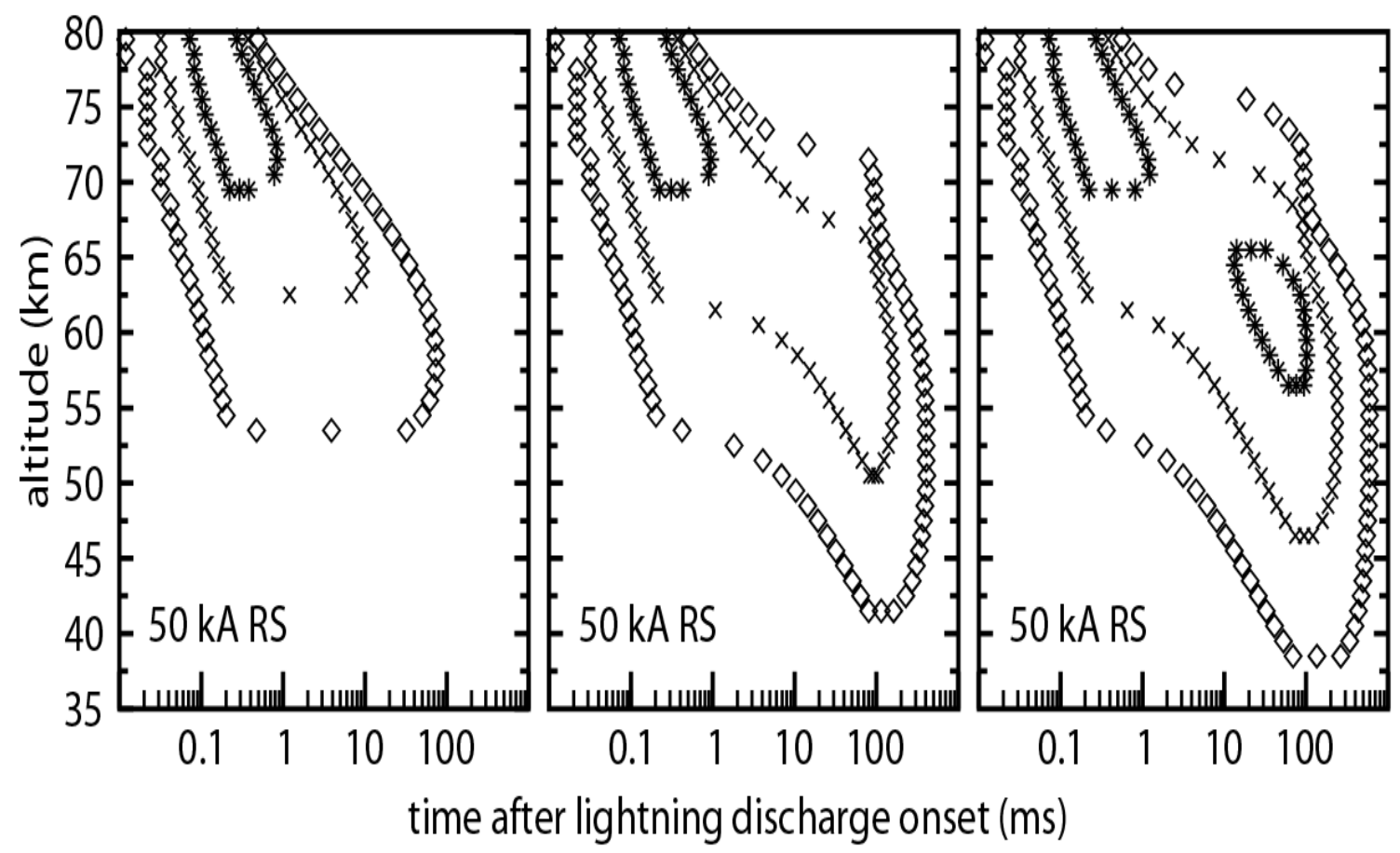

Fig. 5. Diagram showing the temporal evolution of regions of electrical breakdown, which occurs within the starred areas, above and at different times after a lightning return stroke (RS) of $50 \mathrm{kA}$. From the ionosphere at $80 \mathrm{~km}$ down to $68 \mathrm{~km}$, this indicates a column (columniform) sprite up to $1 \mathrm{~ms}$ after the lightning. Downwards propagating positive streamers can be sustained within the area formed by diamonds, and upward propagating negative streamers within the area formed by crosses. (a) is for a continuing current (CC), lasting $90 \mathrm{~ms}$, of only $0.2 \mathrm{kA}$, (b) for a CC of $0.5 \mathrm{kA}$, and (c) for a CC of 2 $\mathrm{kA}$. Only for the latter large $\mathrm{CC}$ does an electrical discharge occur, from $66 \mathrm{~km}$ down to $57 \mathrm{~km}$, from 10 to $60 \mathrm{~ms}$ after the lightning onset; this represents a carrot sprite. 
(a)
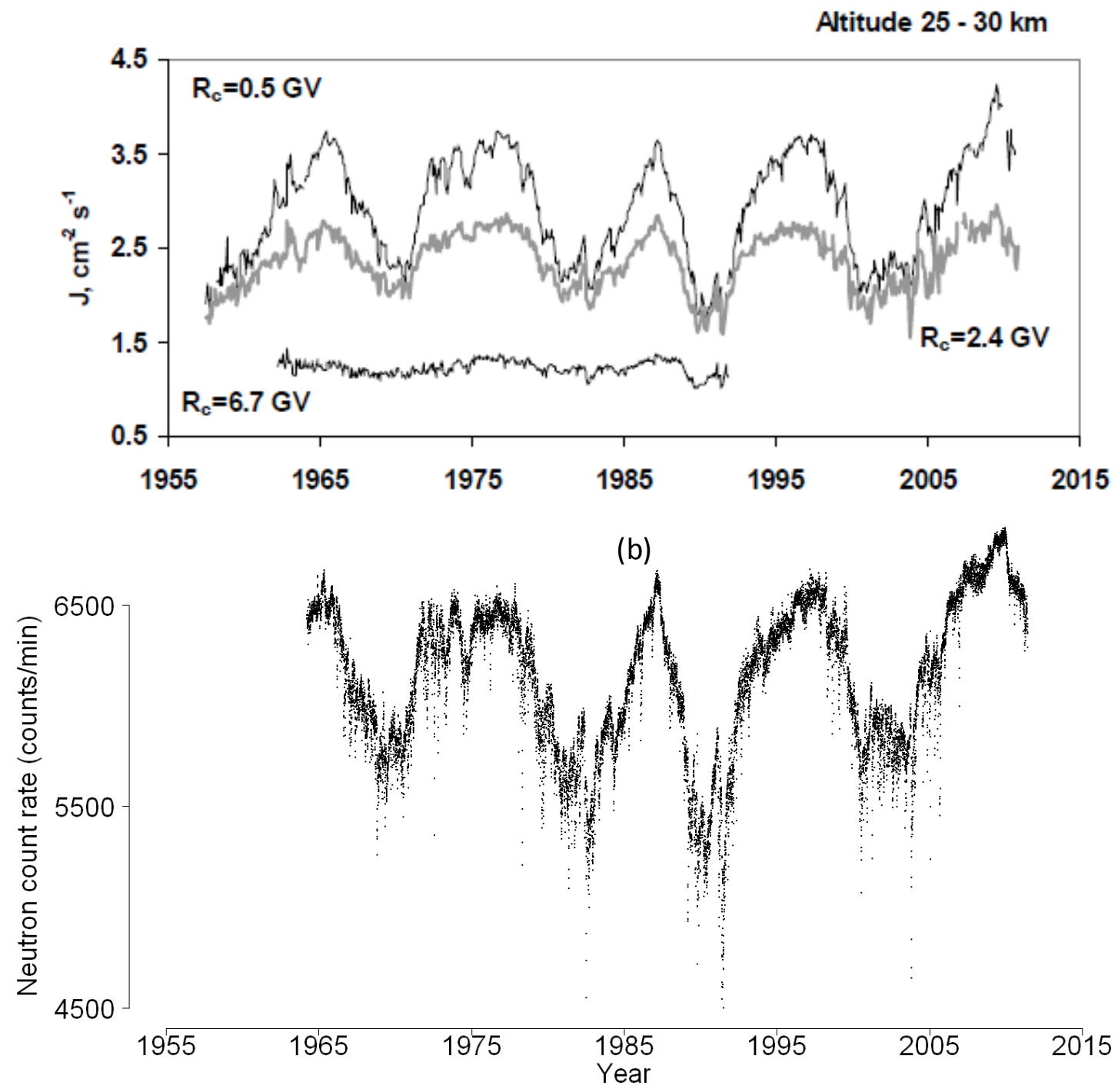

Fig. 6. (a) Monthly average values of omnidirectional flux of cosmic rays $\mathrm{J}$, at altitudes between 25 and $30 \mathrm{~km}$, measured from balloons flown by the Lebedev Institute in Moscow, Russia (Stozhkov et al 2009, updated to the present time). Different lines represent separate measurement locations, at geomagnetic latitudes of $33^{\circ}$ (cut off rigidity $\left.\mathrm{R}_{\mathrm{c}}=6.7 \mathrm{GV}\right), 51^{\circ}(2.4 \mathrm{GV})$ and $64^{\circ}(0.6 \mathrm{GV})$. (b) The neutron monitor count rate from Oulu, Finland $(\mathrm{Rc}=0.8 \mathrm{GV})$, available from http://cosmicrays.oulu.fi/, during the same time period as (a). The similarity between (b) and the lowest rigidity data presented in (a), as the 11 year solar cycle waxes and wanes, is extremely clear. 
(a) 1969-1972

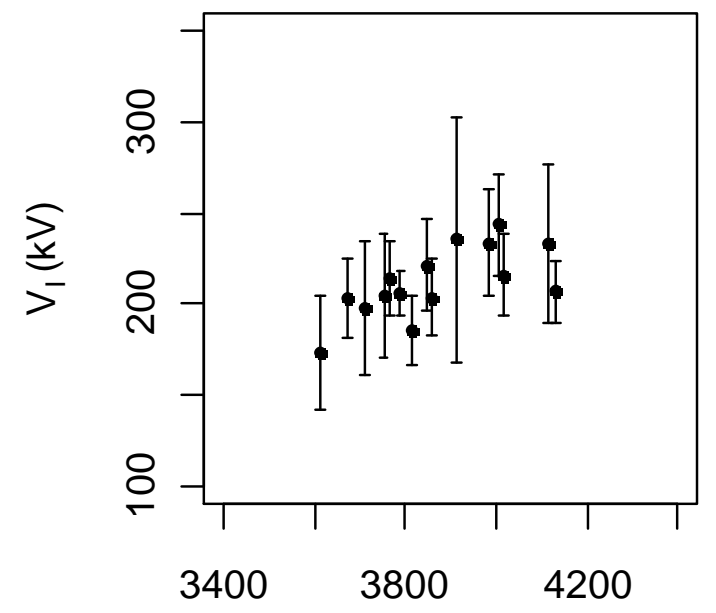

Climax neutron rate $\left(\times 10^{2} \mathrm{hr}^{-1}\right)$

(b) 1966-1979

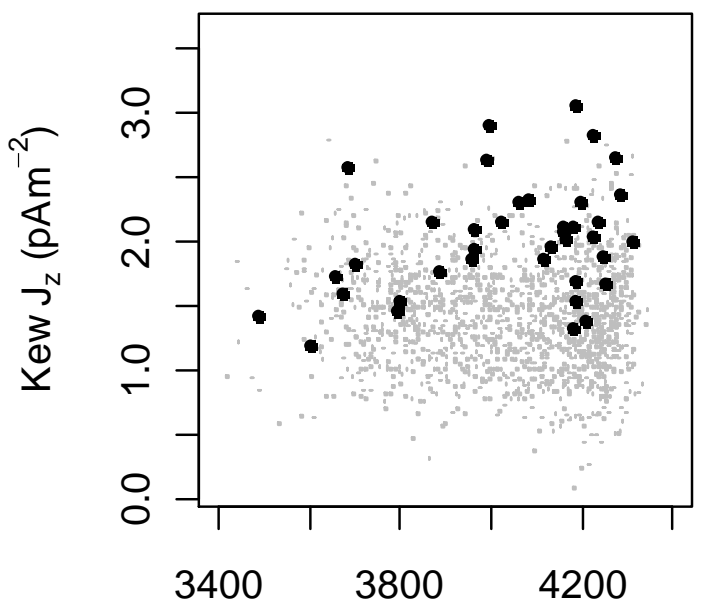

Climax neutron rate $\left(\times 10^{2} \mathrm{hr}^{-1}\right)$

Figure 7. Comparison of Climax neutron counter data with (a) ionospheric potential $\left(\mathrm{V}_{\mathrm{I}}\right)$ measured from 1966-1972 (from Harrison and Usoskin, 2010), for months having 4 or more $V_{I}$ measurements available (error bars represent two standard errors) and (b) daily fair weather conduction current density measurements $J_{z}$ determined at Kew (London) between 1966 and 1979 (Harrison and Ingram, 2005). In (b), measurements obtained on days having the highest ("clean") surface air conductivity (greater than $8.9 \mathrm{fS} \mathrm{m}^{-1}$ ) have been identified with black points. 


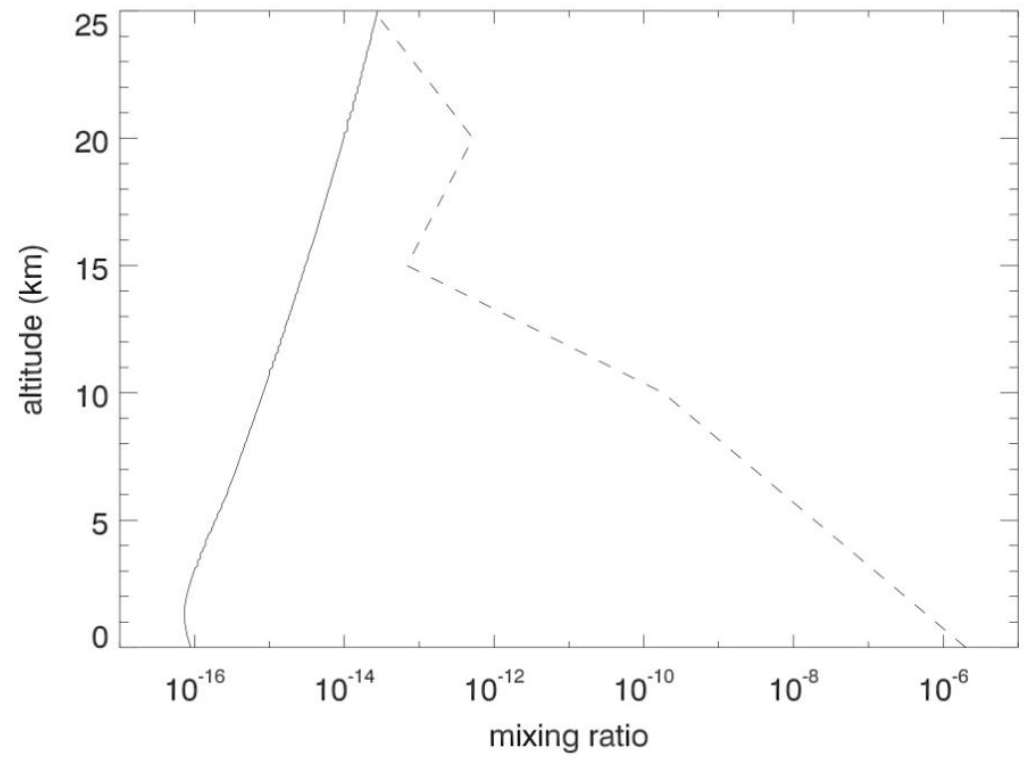

Figure 8. Mixing ratio of ion clusters (solid line) and the water vapour dimer (dashed line) in the troposphere and lower stratosphere. The predicted water vapour dimer concentration is taken from Kjaergaard et al (2003) and the ion cluster concentration, for an aerosol-free atmosphere, is from the parameterisation of Makino and Ogawa (1985). Mixing ratios were calculated with respect to the US Standard Atmosphere. 


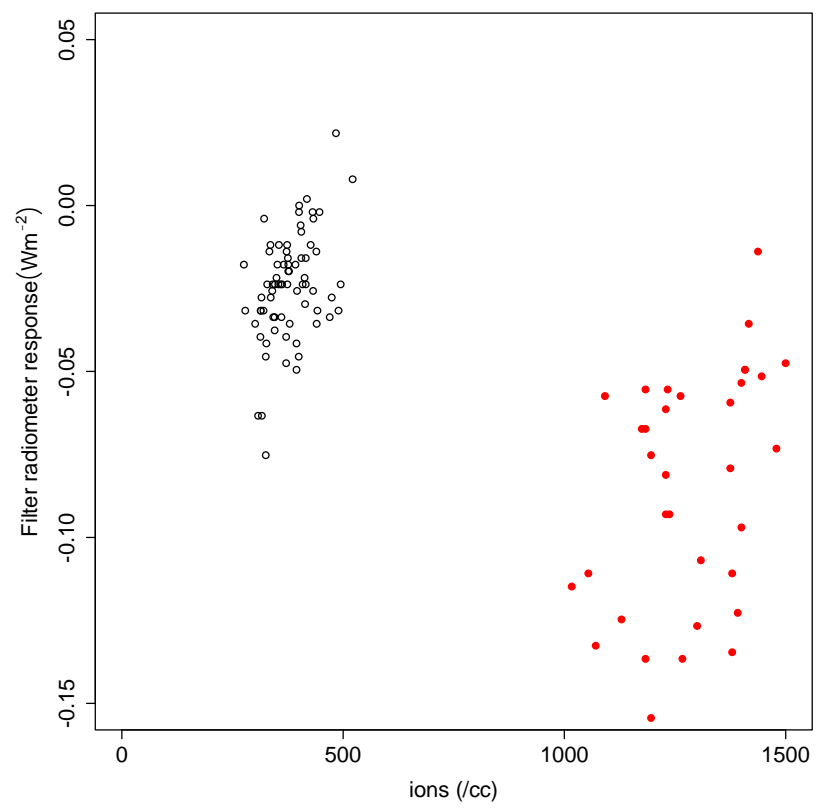

Fig. 9. Filter radiometer response to atmospheric ion concentrations on two days in 2007, for five minute averages during clear conditions on day 112 (from 01 to 04 UT on $22^{\text {nd }}$ April 2007) (red closed circles) and during fog on day 309 (from 00 to 06 UT on $5^{\text {th }}$ November 2007) (black open circles). If a linear response is assumed, the gradient for day 309 is $130 \pm 30 \mu \mathrm{Wm}^{-2}$ per ion, and for day 112 it is $140 \pm 50 \mu \mathrm{Wm}^{-2}$ per ion 
(a)

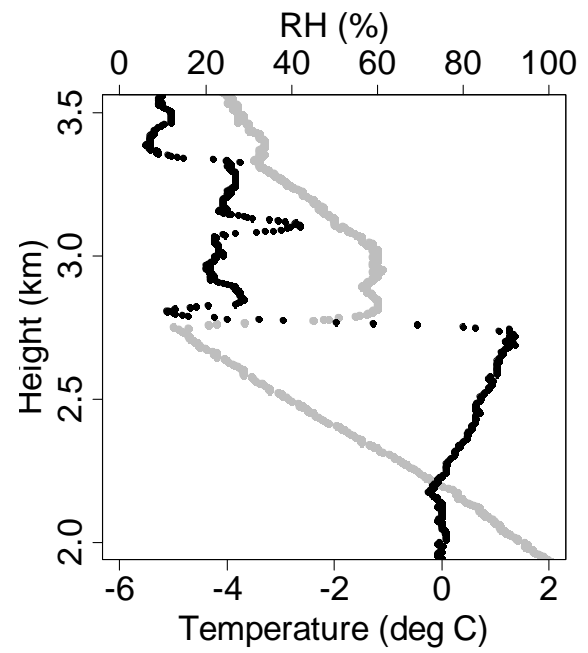

(c)

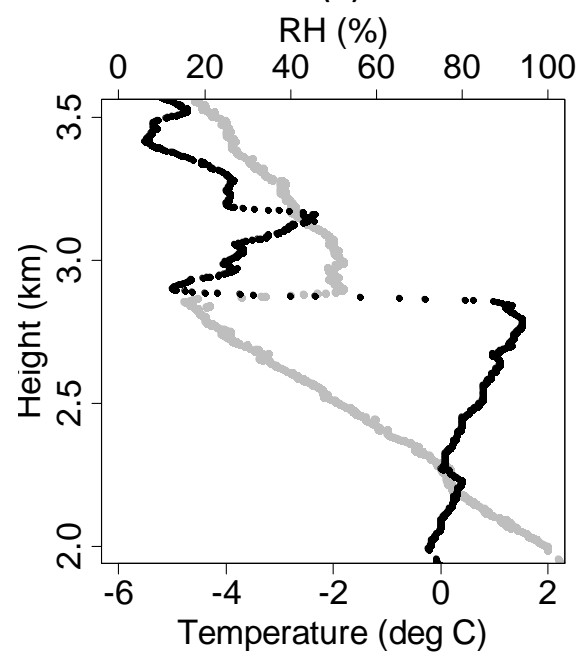

(b)

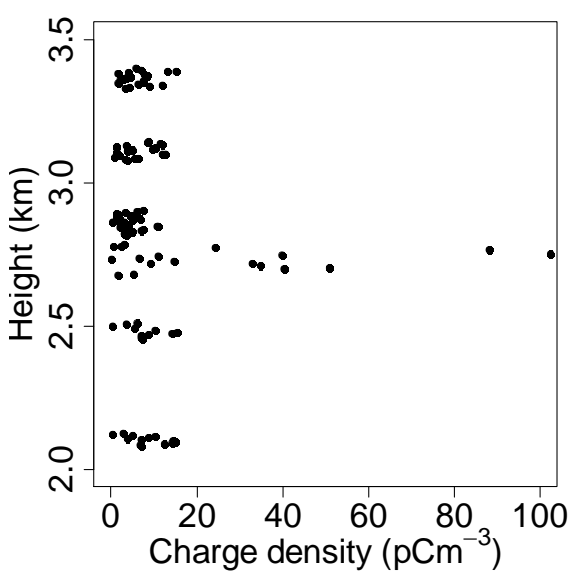

(d)

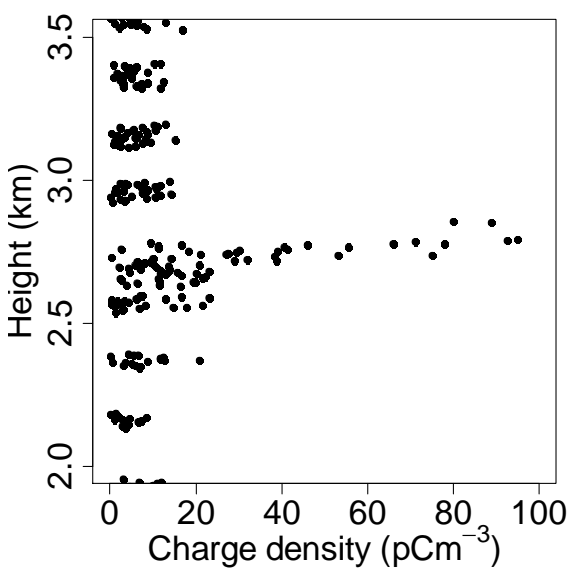

Fig. 10. Vertical profiles from the ascent ((a), (b)) and descent ((c), (d)) of an instrumented balloon flight through a layer of stratocumulus cloud over the U.K., during July 2009. (a) and (c) denote temperature (grey) and relative humidity (RH) (black) measured by a standard meteorological radiosonde, (b) and (d) show the magnitude of the space charge density measured by a charge sensor on the same flight. The horizontal distance travelled by the balloon between the ascent and descent passage through the cloud layer was about $65 \mathrm{~km}$; thus, the similarity between (a) and (c) indicates that this was a large, uniform low level cloud layer. (Adapted from Nicoll (2010).) 
(a)

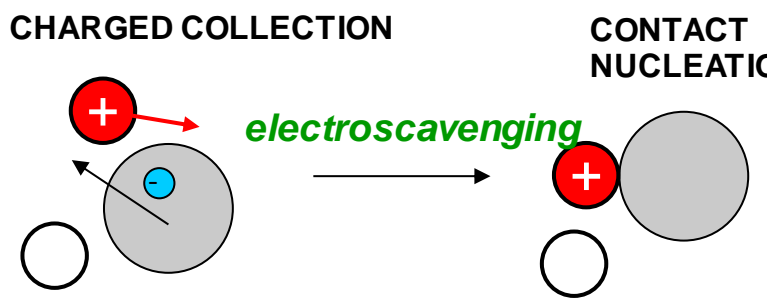

CONTACT

EATION

(b)

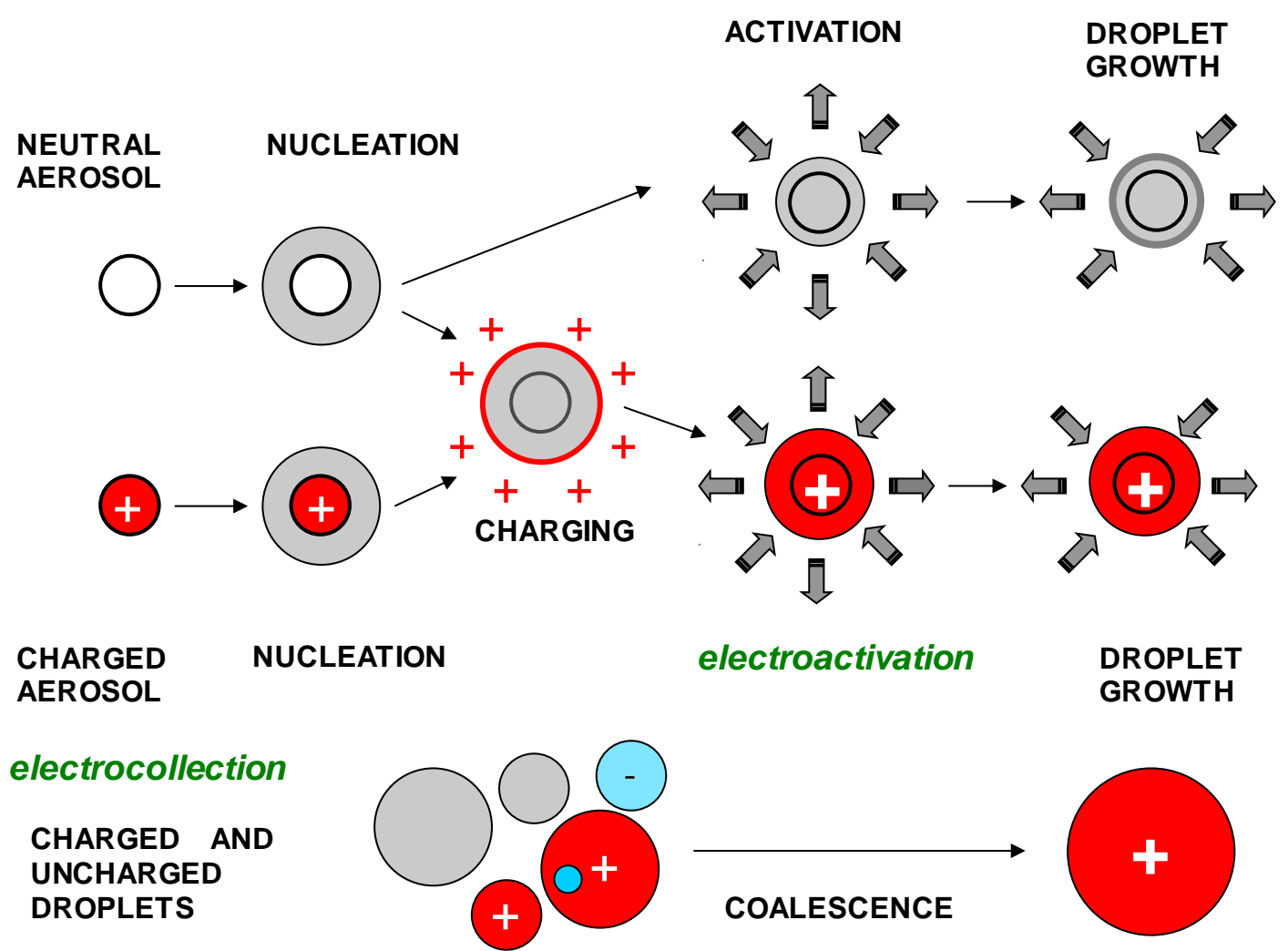

Fig. 11. Diagram showing various cloud microphysical processes which may be affected by electrical charge. (a) demonstrates electro-scavenging, whereby charged aerosol particles (red) are more likely to become scavenged by water droplets (grey) than neutral particles (white). If the particle is an ice nucleus, and the droplet is supercooled, freezing can occur on contact (a process known as electrofreezing). (b) shows electroactivation, whereby the presence of charge stabilises the growing droplet, and inhibits evaporation, decreasing the critical supersaturation at which pure cloud droplets activate. The arrows represent condensation and evaporation which are occurring simultaneously. (c) shows electrocollection, whereby the collision efficiency for droplet-droplet collisions can be increased when at least one of the droplets is charged, thereby increasing the rate of growth of cloud droplets 

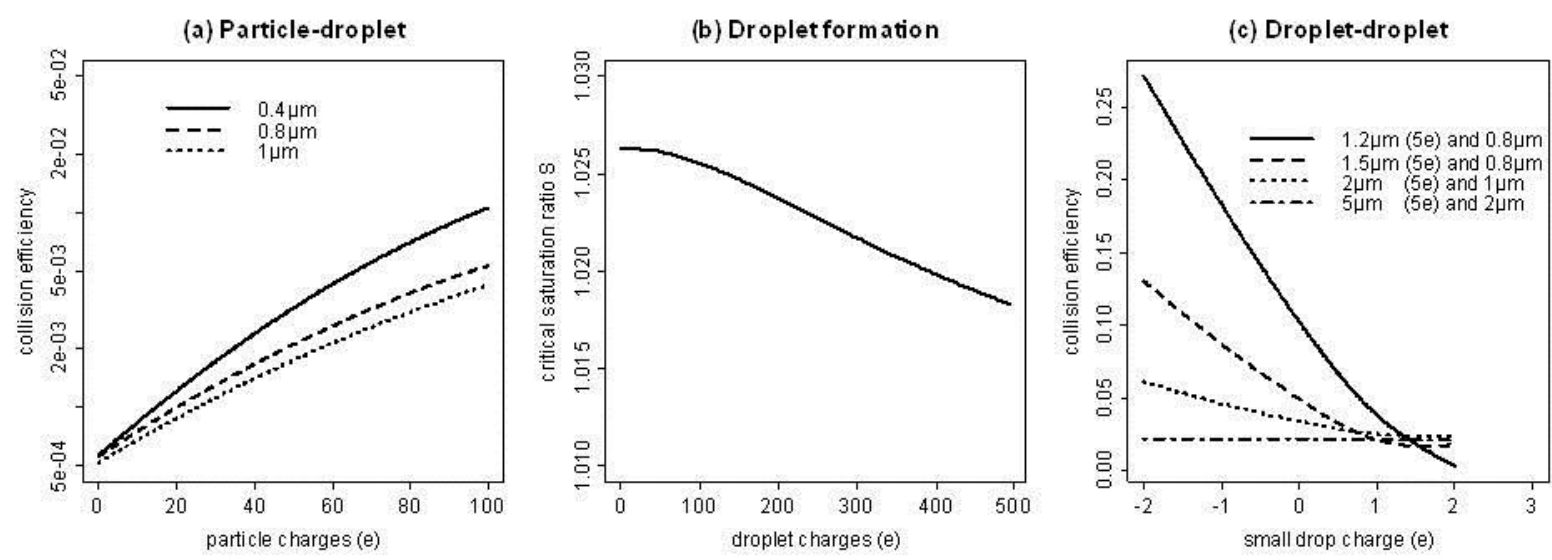

Fig. 12. (a) Collision efficiency between a neutral $50 \mu \mathrm{m}$ radius water drop and a charged particle (density $1.5 \mathrm{gm}^{-3}$ ) for three small radii, for which the particle charge is allowed to vary, calculated using the parameterisation of Tripathi et al (2006). (b) Variation of critical supersaturation (the supersaturation at which a droplet becomes activated) with droplet charge, for a pure water droplet containing only $2.5 \times 10^{-21} \mathrm{~kg}$ of sodium chloride (Harrison and Ambaum, 2008). (c) Collision efficiency between a pair of water droplets of selected radii, the larger of which carries 5 elementary charges and the smaller a variable charge of either polarity, in an electric field of magnitude $100 \mathrm{Vm}^{-1}$, calculated from the model of Klimin et al (1994). 